NBER WORKING PAPER SERIES

\title{
MULTILATERAL TRADE BARGAINING: \\ A FIRST LOOK AT THE GATT BARGAINING RECORDS
}

\author{
Kyle Bagwell \\ Robert W. Staiger \\ Ali Yurukoglu \\ Working Paper 21488 \\ http://www.nber.org/papers/w21488
NATIONAL BUREAU OF ECONOMIC RESEARCH
1050 Massachusetts Avenue
Cambridge, MA 02138

August 2015

We thank the NSF (Grant SES-1326940) and SEED for financial support, and Sushan Demirjian, Diwakar Dixit, Anwarul Hoda, Lee Ann Jackson, Amelia Porges, William Powers and Suja Rishikesh for very helpful discussions related to various aspects of this project. We are especially grateful to Ambassador Julio Lacarte Muró for patiently answering our many questions about the mechanics of the early GATT rounds. We also thank Jakub Kastl, Nuno Limao, Marcelo Olarreaga, Marzena Rostek, Michele Ruta and seminar participants at Berkeley, Dartmouth, Indiana, Maryland, Princeton, Stanford, Yale and The World Bank as well as participants at the Dartmouth-SNU conference on International Trade Policy and Institutions and the NBER 2015 ITI Summer Institute for very helpful comments. Patricia Abbott, Ayako Obashi, Woan Foong Wong and Junhui Zeng provided outstanding research assistance, as did Joanna Yeo, Zhufei Shi, and especially Elizabeth Stone on earlier phases of the data processing portion of this project. Bagwell thanks CASBS at Stanford for support and hospitality. The views expressed herein are those of the authors and do not necessarily reflect the views of the National Bureau of Economic Research.

At least one co-author has disclosed a financial relationship of potential relevance for this research. Further information is available online at http://www.nber.org/papers/w21488.ack

NBER working papers are circulated for discussion and comment purposes. They have not been peerreviewed or been subject to the review by the NBER Board of Directors that accompanies official NBER publications.

(C) 2015 by Kyle Bagwell, Robert W. Staiger, and Ali Yurukoglu. All rights reserved. Short sections of text, not to exceed two paragraphs, may be quoted without explicit permission provided that full credit, including $(\mathcal{C}$ notice, is given to the source. 
Multilateral Trade Bargaining: A First Look at the GATT Bargaining Records

Kyle Bagwell, Robert W. Staiger, and Ali Yurukoglu

NBER Working Paper No. 21488

August 2015

JEL No. C78,D02,F13

\begin{abstract}
$\underline{\text { ABSTRACT }}$
This paper empirically examines recently declassified data from the GATT/WTO on tariff bargaining. We document eight stylized facts about these interconnected high-stakes international negotiations. We use detailed product-level offer and counteroffer data to examine several questions about trade policy, including whether preferential tariffs were a stumbling block towards liberalization, and whether the relaxation of bilateral reciprocity to multilateral reciprocity aided liberalization. We organize the empirical analysis around a theoretical model of multi-party trade negotiations motivated by the terms-of-trade theory and respecting the institutional features of most-favored-nation status and reciprocity.
\end{abstract}

Kyle Bagwell

Department of Economics

Stanford University

Landau Economics Building

579 Serra Mall

Stanford, CA 94305-6072

and NBER

kbagwell@stanford.edu

Robert W. Staiger

Department of Economics

Dartmouth College

319 Silsby

Hanover, NH 03755

and NBER

rstaiger@dartmouth.edu

\author{
Ali Yurukoglu \\ Graduate School of Business \\ Stanford University \\ Stanford, CA 94305 \\ and NBER \\ yurukoglu_ali@gsb.stanford.edu
}




\section{Introduction}

The World Trade Organization (WTO) and its predecessor the General Agreement on Tariffs and Trade $(\mathrm{GATT})^{1}$ have presided over the largest and most sustained negotiated trade liberalization in history. Yet challenges remain, as evidenced by the 13-year-long Doha Round of multilateral trade negotiations now certain to fall far short of its initial aspirations. This paper introduces and empirically analyzes detailed negotiation data, recently declassified by the WTO, to understand the nature of tariff bargaining in the world trading system. Improving our understanding of these negotiations is important for addressing the challenges facing modern trade agreements. At the same time, analyzing these detailed offer data in high stakes international negotiations contributes to economists' understanding of bargaining more generally.

GATT/WTO tariff negotiations display several notable features. The negotiations are a form of barter, whereby governments accept commitments on their own import tariffs in exchange for the reciprocal tariff commitments of their principal trading partners. For each round a specific bargaining protocol is adopted, with explicit rules for the timing of events, the kinds of interactions expected and the exchange of information among participants. And though it is a multilateral institution, for the most part the GATT/WTO has adopted a bilateral approach to multilateral tariff bargaining according to which reciprocal "request-offer" negotiations occur on a voluntary basis between pairs of countries at the tariff-line level, with the results of these bilateral negotiations then "multilateralized" to the full GATT/WTO membership by a non-discrimination requirement that tariffs abide by the most-favored nation (MFN) principle.

Our empirical analysis has two major components, both of which focus on the US bilateral negotiations at the Torquay (1950-1951) Round. We first describe the salient features of these high stakes negotiations: How many tariff-cut offers are made?; How large are the offers?; Which countries receive offers on which goods?; How do offers evolve over the course of negotiations?; and so on. Then we ask a series of classic trade policy questions: Does the multilateralization of trade bargaining aid liberalization?; Are preferential tariffs a building block or stumbling block towards liberalization?; Are negotiating patterns consistent with the terms-of-trade theory? With these two components we show how the new data present a major research opportunity for economists interested in international trade policy, economic history, or bargaining theory.

\footnotetext{
${ }^{1}$ The GATT was created in 1947, and it sponsored a total of eight multilateral negotiating rounds through 1994. With the conclusion of the eighth (Uruguay) round, the WTO came into existence on January 1, 1995, and it includes the GATT and a set of additional agreements that extend GATT principles to new areas.
} 
To structure our empirical analysis, we establish a theoretical and institutional framework. This framework adopts the perspective of the terms-of-trade theory of trade agreements (see Bagwell and Staiger, 2010a, for a recent review of the central features of this theory). On top of the basic theory, we layer the institutional features of reciprocity and MFN. Reciprocity requires that equilibrium agreements increase export volume for a given country by the same amount as the increase in its import volume. MFN requires that any concession granted in a bilateral negotiation be extended unconditionally to the other members of GATT.

With this framework established, we document a series of stylized facts about the negotiations. We find that the numbers of back-and-forth offers and counter-offers in any bargain are relatively small, and that the bargaining appears to have taken the form of essentially take-itor-leave-it offers on the intensive margin (the level of the tariff cut offered) and back-and-forth offers and counter-offers on the extensive margin (which products are to be included in the bargain). We document that countries make counter-proposals by adjusting the set of tariff cuts they offer, but do not propose adjustments to what their bargaining partners have offered. Substantial numbers of offers are made that were not requested by the country to which the offer is extended, and some offers are made that were not requested by any country at all. There is substantial two-way bargaining within narrow product categories, and significant numbers of these two-way bargains occur within a single bilateral. The biggest supplying countries play the dominant role in negotiations, but the role of smaller supplying countries can also be significant. The set of requests a country entertains seems to conform with principal supplier considerations, but when it comes to deciding which bargaining partners to make requests of on a given product there appears to be a more narrow focus than principal supplier considerations would dictate. And initial offers can sit dormant for long periods only to be finalized with a single modification at the time that other bargains are concluded.

After establishing these stylized facts, we turn to analyzing the role of multilateralism in the negotiations. While negotiations occurred bilaterally, the fact that they were occurring simultaneously and in geographic proximity to each other allowed the possibility that some negotiations might succeed by building on others. Put simply, if country A wants a concession from country B, and country B from country C, and country C from country A, negotiation outcomes that respect bilateral reciprocity would fail whereas bilateral negotiations which respect only multilateral reciprocity can succeed. Indeed, writings from the time placed great emphasis on the role of GATT in facilitating multilateral as opposed to bilateral reciprocity, as 
illustrated by this exert from an early GATT report (see also Curzon, 1966, pp. 75-77):

Multilateral tariff bargaining, as devised at the London Session of the Preparatory Committee in October 1946 and as worked out in practice at Geneva and Annecy, is one of the most remarkable developments in economic relations between nations that has occurred in our time. It has produced a technique whereby governments, in determining the concessions they are prepared to offer, are able to take into account the indirect benefits they may expect to gain as a result of simultaneous negotiations between other countries, and whereby world tariffs may be scaled down within a remarkably short time. (ICITO, 1949, p. 10)

We look for evidence that GATT played this role using the offer and counteroffer data from Torquay, and we exploit a "natural experiment": the breakdown of the US-UK bilateral midway through the round. Specifically, we test whether, after this breakdown, the offers on the table in the remaining US bilaterals were adjusted to compensate for the disappearance of expected indirect benefits from the US-UK bilateral. Our findings support this view. We find that goods which the US was negotiating with the UK were more likely to be revised into new US offers to other countries following the breakdown at the same time that these other countries were withdrawing offers to the US, indicating that these other countries had been counting on concessions from negotiations to which they were not party.

We close by modeling the decision to make an offer on a product, and the success of the offer in becoming a finalized concession. We focus on US offers, and use a specification that is suggested by our theoretical and institutional framework, modeling these outcomes at the product level as functions of the exporter concentration of the product into the US, the extent to which major exporters of the product to the US were members of a preferential tariff agreement (PTA) with third countries, the extent to which the US had a reciprocal desire for tariff cuts from the major exporters of the product into the US, the fraction of exports of the product to the US that came from countries that were not present at Torquay, the degree of product differentiation, a product-level measure of importer market power exerted by the US, whether any country requested a tariff concession from the US on the product, and whether the US had bound the product's tariff in a previous GATT negotiating round.

From the specification of these offer and failure equations, we find that the US was more likely to make offers, and these offers were more likely to succeed, when the US measure of 
importer market power is higher. This finding supports the basic premise of the terms-of-trade theory. Our findings regarding PTAs are more guarded: we find that the US was more likely to make offers on products where a PTA member was a major supplier of that product to the US market; but we also find that those offers were more likely to fail. On net, the first effect outweighs the second, and so our findings lend support to the view that PTAs were building blocks for US liberalization at Torquay. We do not find evidence in either our offer or failure equation that the US faced a major free-rider problem associated with MFN, which is in line with the predictions of the terms-of-trade theory when MFN is combined with reciprocity.

A focus on the US Torquay bilaterals keeps the data set manageable while still allowing us to study the multilateral bargaining behavior of one of the major players in GATT. But can lessons learned from a 65-year-old GATT round have relevance for the modern era? We believe so, for at least two reasons. First, in its Torquay bargains the US was faced with a set of trade bargaining challenges that have clear counterparts today: approaching the potential bargaining externalities associated with MFN, addressing the existence of preferential tariffs, and dealing with asymmetries in the tariff levels across countries at different stages of development and with different negotiating histories. And second, the basic features of the bargaining protocol adopted at Torquay are still very much in use: for example, a similar protocol has been adopted in the Doha Round for market access negotiations in the critical area of trade in services. ${ }^{2}$

Our paper is related to several literatures. Recent papers in international trade have asked whether there is empirical support for the terms-of-trade theory of trade agreements (e.g., Broda, Limao and Weinstein, 2008, Bagwell and Staiger, 2011, Ludema and Mayda, 2013, Bown and Crowley, 2013), whether MFN creates a free-rider problem for trade negotiations (e.g., Ludema and Mayda, 2009, 2013 ), and whether PTAs create building blocks or stumbling blocks for multilateral liberalization (e.g., Limao, 2006, Karacaovali and Limao, 2008, Estevadeordal, Freund and Ornelas, 2008). And economic historians and political scientists have long debated what made GATT special as an institution for promoting trade liberalization (e.g., Irwin, 1995, and Gowa and Kim, 2005). Our paper provides evidence on each of these questions, but for the first time from the perspective of actual tariff bargaining data.

In the context of the empirical bargaining literature, a handful of papers empirically examine bilateral bargaining with not just outcome data, but detailed offer and counter-offer data. These

\footnotetext{
${ }^{2}$ The Doha protocol for market access negotiations over trade in services shares the same bilateral requestoffer format as the Torquay protocol, though the Doha rules for the exchange of information across bilaterals appear to have evolved somewhat. See, for example, Feketekuty (2008), WTO (2001) and WTO (2002).
} 
include Keniston (2013) and Larsen (2014). In these settings, bilateral negotiations do not affect payoffs of parties not involved in the bargain. In parallel, there is an emergent literature in industrial organization empirically examining bilateral bargaining with externalities using data on only outcomes as in Crawford and Yurukoglu (2012). Our paper is unique in looking at detailed offer and counter-offer data in a setting of bilateral bargaining with externalities.

The remainder of the paper proceeds as follows. In section 2 we present the basic theory of trade negotiations that guides our empirical analysis of the GATT bargaining data. We describe the GATT bargaining protocols in section 3, and in section 4 we discuss the broad features of the GATT bargaining data. In section 5 we present summary statistics relating to the US Torquay bilaterals and describe stylized facts about multilateral tariff bargaining that are suggested by these bargaining records. In sections 6 and 7 we draw on our theoretical framework and present our empirical analysis of multilateralism in the negotiations and the determinants of offers and bargaining failure. Section 8 concludes.

\section{The Theory of Trade Negotiations}

In this section, we present the theory of trade negotiations that guides our empirical analysis.

\subsection{The Trade Negotiation Problem}

We begin by reviewing the textbook two-good general-equilibrium model of trade between two countries, defining a general family of government preferences, and using the resulting framework to identify the problem that a trade agreement can solve. For this purpose we paraphrase the treatment in Bagwell and Staiger (2010a), and refer readers there for details.

The Model Two countries, domestic (no *) and foreign $(*)$, trade two goods which are normal in consumption and produced in perfectly competitive markets under conditions of increasing opportunity costs. We let $x(y)$ denote the natural import good of the domestic (foreign) country. The local relative price facing domestic (foreign) producers and consumers is defined as $p \equiv p_{x} / p_{y}\left(p^{*} \equiv p_{x}^{*} / p_{y}^{*}\right)$. Tariffs are non-prohibitive, and we represent the domestic (foreign) ad valorem import tariff as $t\left(t^{*}\right)$. Letting $\tau \equiv(1+t)$ and $\tau^{*} \equiv\left(1+t^{*}\right)$, we then have that $p=\tau p^{w} \equiv p\left(\tau, p^{w}\right)$ and $p^{*}=p^{w} / \tau^{*} \equiv p^{*}\left(\tau^{*}, p^{w}\right)$, where $p^{w} \equiv p_{x}^{*} / p_{y}$ is the "world" (i.e., untaxed) relative price. The foreign terms of trade is given by $p^{w}$, and the domestic terms of trade is $1 / p^{w}$. We interpret $\tau>1$ as an import tax and similarly for $\tau^{*}$. 
In each country, production levels for $x$ and $y$ are determined by the local relative price: $Q_{i}=Q_{i}(p)$ and $Q_{i}^{*}=Q_{i}^{*}\left(p^{*}\right)$ for $i=\{x, y\}$. Consumption is also influenced by the local relative price, which defines the trade-off faced by consumers and determines the level and distribution of factor income. Consumption depends as well on tariff revenue $R\left(R^{*}\right)$, which is measured in units of the local export good at local prices and is distributed lump-sum to domestic (foreign) consumers. Domestic and foreign consumption thus may be represented as $D_{i}=D_{i}(p, R)$ and $D_{i}^{*}=D_{i}^{*}\left(p^{*}, R^{*}\right)$ for $i=\{x, y\}$. But tariff revenue is implicitly defined by $R=\left[D_{x}(p, R)-Q_{x}(p)\right]\left[p-p^{w}\right]$ or $R=R\left(p, p^{w}\right)$ for the domestic country, and similarly we have that $R^{*}=\left[D_{y}^{*}\left(p^{*}, R^{*}\right)-Q_{y}^{*}\left(p^{*}\right)\right]\left[1 / p^{*}-1 / p^{w}\right]$ or $R^{*}=R^{*}\left(p^{*}, p^{w}\right)$ for the foreign country; and each country's tariff revenue increases with its terms of trade, given our assumption of normal goods. Hence, we may express national consumption as a function of local and world prices: $C_{i}\left(p, p^{w}\right) \equiv D_{i}\left(p, R\left(p, p^{w}\right)\right)$ and $C_{i}^{*}\left(p^{*}, p^{w}\right) \equiv D_{i}^{*}\left(p^{*}, R^{*}\left(p^{*}, p^{w}\right)\right)$ for $i=\{x, y\}$.

Imports of $x$ and exports of $y$ for the domestic country are respectively defined by $M\left(p, p^{w}\right) \equiv$ $C_{x}\left(p, p^{w}\right)-Q_{x}(p)$ and $E\left(p, p^{w}\right) \equiv Q_{y}(p)-C_{y}\left(p, p^{w}\right)$. Likewise, for the foreign country, we have $M^{*}\left(p^{*}, p^{w}\right)$ and $E^{*}\left(p^{*}, p^{w}\right)$, respectively. For any prices, domestic and foreign budget constraints are represented by the trade-balance equations:

$$
p^{w} M\left(p, p^{w}\right)=E\left(p, p^{w}\right) \text {, and } M^{*}\left(p^{*}, p^{w}\right)=p^{w} E^{*}\left(p^{*}, p^{w}\right) .
$$

The equilibrium world price, $\widetilde{p}^{w}\left(\tau, \tau^{*}\right)$, is determined by market clearing for good $y$ :

$$
E\left(p\left(\tau, \widetilde{p}^{w}\right), \widetilde{p}^{w}\right)=M^{*}\left(p^{*}\left(\tau^{*}, \widetilde{p}^{w}\right), \widetilde{p}^{w}\right),
$$

where we make explicit in (2.2) the functional dependencies for local prices. Market clearing for good $x$ is then guaranteed by (2.1) and (2.2).

We assume $d p / d \tau>0>d p^{*} / d \tau^{*}$ and $\partial \widetilde{p}^{w} / \partial \tau<0<\partial \widetilde{p}^{w} / \partial \tau^{*}$, thereby ruling out the Metzler and Lerner paradoxes, and with the final two inequalities indicating that each country is "large" (i.e., each country can improve its terms of trade by increasing its tariff).

Government Preferences The traditional approach to representing government preferences is to impose the assumption that governments maximize national income; by contrast, in the political-economy approach, governments are motivated by distributional concerns. Here, we follow Bagwell and Staiger (1999, 2002) and adopt a general approach to modeling government preferences, representing the objectives of the domestic and foreign governments with the general functions $W\left(p, \widetilde{p}^{w}\right)$ and $W^{*}\left(p^{*}, \widetilde{p}^{w}\right)$, respectively. We thus represent welfare in terms of 
the prices that the tariffs induce rather than directly in terms of the tariffs themselves. This approach enables us to disentangle the separate roles played by the terms-of-trade externality and political motivations in explaining the purpose of a trade agreement.

We place no restrictions on government preferences over local prices: as local prices determine the level and distribution of factor incomes, we therefore accommodate a wide range of political motivations. We assume only that, holding its local price fixed, each government is pleased when its terms of trade improve:

$$
W_{\widetilde{p}^{w}}<0 \text { and } W_{\widetilde{p}^{w}}^{*}>0
$$

The meaning of (2.3) in terms of the underlying tariff changes is that a government values the international income transfer that is implied by an increase in its own tariff and a decrease in the tariff of its trading partner that together leave its local price unaltered. As Bagwell and Staiger (1999, 2002) discuss, governments maximize welfare functions of this form in both the traditional approach and in the leading political-economy approaches to trade policy.

Unilateral Policies To analyze optimal unilateral (non-cooperative) policies, we suppose that each government sets its tariff policy to maximize its welfare, for any given tariff choice of its trading partner. The associated tariff reaction curves are defined implicitly by

$$
\begin{gathered}
W_{p}+\lambda W_{\widetilde{p}^{w}}=0, \text { and } \\
W_{p^{*}}^{*}+\lambda^{*} W_{\widetilde{p}^{w}}^{*}=0,
\end{gathered}
$$

where $\lambda \equiv\left[\partial \widetilde{p}^{w} / \partial \tau\right] /[d p / d \tau]<0$ and $\lambda^{*} \equiv\left[\partial \widetilde{p}^{w} / \partial \tau^{*}\right] /\left[d p^{*} / d \tau^{*}\right]<0$. As these expressions highlight, the best-response tariff of each government strikes a balance between the effects on its welfare of the local- and world-price movements induced by its tariff choice. ${ }^{3}$

The welfare implications of the local-price movement in the first term of (2.4) are domestic in nature: they reflect the trade-off for the domestic government between the costs of the induced economic distortions and the benefits of any induced political support. By contrast, the welfare implications of the world-price movement in the second term of (2.4) are international in nature: they reflect the benefits to the domestic government of shifting some of the costs of its policy choice onto the foreign government. Cost shifting occurs, since any improvement in

\footnotetext{
${ }^{3}$ We assume throughout that the second-order conditions associated with any maximization problem hold globally.
} 
the domestic country's terms of trade is a deterioration in the foreign country's terms of trade. We may similarly interpret (2.5) for the foreign government.

In a Nash equilibrium, both governments are on their reaction curves, and a Nash equilibrium tariff pair $\left(\tau^{N}, \tau^{* N}\right)$ thus satisfies (2.4) and (2.5). We take this equilibrium to represent the trade-policy decisions that governments would make if there were no trade agreement.

Trade Agreement Governments value a trade agreement if it leads to changes in trade policies that generate Pareto improvements for governments relative to their welfare in the Nash equilibrium. Thus, a trade agreement is potentially valuable if and only if the Nash equilibrium is inefficient, when efficiency is measured relative to government preferences.

Three observations can be stated. ${ }^{4}$ First, Nash tariffs are indeed inefficient. Second, both governments can gain relative to Nash only if each agrees to set its tariff below its Nash level. The first observation means that a mutually beneficial trade agreement is possible, while the second observation implies that reciprocal trade liberalization is necessary for mutual gains. Intuitively, when a government contemplates an increase in its unilateral tariff, it foresees an improvement in its terms of trade; thus, it is in part motivated by the prospect of shifting some of the costs of the tariff hike onto its trading partner. The incentive to shift costs naturally leads governments to set tariffs that are higher than is efficient.

To see if the terms-of-trade externality is the only reason for the inefficiency of Nash tariffs, consider a hypothetical world in which governments are not motivated by the terms-of-trade implications of their unilateral trade-policy choices, that is, a hypothetical non-cooperative setting in which $W_{\widetilde{p}^{w}} \equiv 0$ and $W_{\widetilde{p}^{w}}^{*} \equiv 0$. Next define the "domestic politically optimal reaction curve" by $W_{p}=0$, the "foreign politically optimal reaction curve" by $W_{p^{*}}^{*}=0$, and the politically optimal tariffs as any tariff pair $\left(\tau^{P O}, \tau^{* P O}\right)$ that satisfies the first-order conditions $W_{p}=0$ and $W_{p^{*}}^{*}=0$. The third observation is that politically optimal tariffs are efficient (when evaluated with actual government preferences): the terms-of-trade externality is the sole rationale for a trade agreement in this ("terms-of-trade theory") modeling framework.

The politically optimal tariffs are not the only efficient tariffs. In the special case where governments maximize national welfare, efficient tariffs satisfy $\tau=1 / \tau^{*}$ (as Mayer, 1981 shows) and politically optimal tariffs correspond to reciprocal free trade (i.e., $\tau=\tau^{*}=1$ ), a point on the Mayer locus. A trade agreement enables governments to move from the inefficient Nash

\footnotetext{
${ }^{4}$ Formal proofs of these observations can be found in Bagwell and Staiger (1999, 2002).
} 
tariffs to some point on the contract curve, where the contract curve is that portion of the

efficiency frontier on which neither government receives below-Nash welfare. The politically optimal tariffs lie on the contract curve, provided that the countries are not too asymmetric.

\subsection{Reciprocity and MFN: Implications for the GATT bargaining data}

We next consider the implications of the key GATT/WTO institutional features of reciprocity and MFN for tariff bargaining and thus the GATT bargaining data. We note at the outset that there are (at least) two complementary approaches to analyzing the GATT bargaining data. A first approach emphasizes strict adherence to reciprocity and MFN. The benefit of this approach is that it can afford a powerful simplification to the GATT bargaining problem and thereby provide structure to the analysis of the bargaining data. In this paper we emphasize this approach. A second approach confronts the complications that arise when adherence to reciprocity and/or MFN is not strict. This approach uses models of bilateral bargaining with externalities, informed by other institutional features of the GATT bargaining setting, to analyze the bargaining data. We leave this second approach to future work.

We show below that the GATT/WTO pillars of reciprocity and MFN can dramatically simplify the tariff bargaining problem. First, building on the two-country model in section 2.1, we explain that strict adherence to reciprocity simplifies strategic considerations resulting in a dominant bargaining strategy. Second, in a multi-country version of the model, we confirm as well that strict adherence to reciprocity and MFN neutralizes third-party externalities. But there is also a potential cost: if GATT bargaining partners are asymmetric in a sense described below, then strict adherence to reciprocity and MFN also prevents governments from reaching the efficiency frontier. Finally, to provide further structure for our empirical analysis, we also examine the relationship between bilateral and multilateral reciprocity when MFN is satisfied.

Reciprocity We start with a review of the basic properties of reciprocity. For this purpose we again paraphrase the treatment in Bagwell and Staiger (2010a), and refer readers there for details. The GATT/WTO principle of reciprocity refers to the ideal of mutual changes in trade policy which bring about changes in the volume of each country's imports that are equal in magnitude to the changes in the volume of its exports. The notion of reciprocity arises in two places in the GATT/WTO. First, as we discuss in section 3, governments seek a "balance of concessions" as a norm of negotiations, so that there is a rough equivalence 
between the market access value of the tariff cuts offered by one government and the concessions won from its trading partners. Second, when a government seeks to renegotiate, modify or withdraw a previous concession as an original action, GATT Article XXVIII permits affected trading partners to withdraw "substantially equivalent concessions," and thereby to retaliate in a reciprocal manner. Hence, GATT's reciprocity principle describes a fixed terms-of-exchange rule (applied to increases and decreases) for negotiated market access, and fixes the particular terms of exchange at one-for-one. ${ }^{5}$

Continuing with the two-country model developed in section 2.1, we now state a formal definition of reciprocity. Suppose that, beginning from an initial pair of tariffs, $\left(\tau^{0}, \tau^{* 0}\right)$, a tariff negotiation results in a change to a new pair of tariffs, $\left(\tau^{1}, \tau^{* 1}\right)$. Denoting the initial world and domestic local prices as $\widetilde{p}^{w 0} \equiv \widetilde{p}^{w}\left(\tau^{0}, \tau^{* 0}\right)$ and $p^{0} \equiv p\left(\tau^{0}, \widetilde{p}^{w 0}\right)$, and the new world and domestic local prices as $\widetilde{p}^{w 1} \equiv \widetilde{p}^{w}\left(\tau^{1}, \tau^{* 1}\right)$ and $p^{1} \equiv p\left(\tau^{1}, \widetilde{p}^{w 1}\right)$, we say that the tariff changes conform to the principle of reciprocity provided that

$$
\widetilde{p}^{w 0}\left[M\left(p^{1}, \widetilde{p}^{w 1}\right)-M\left(p^{0}, \widetilde{p}^{w 0}\right)\right]=\left[E\left(p^{1}, \widetilde{p}^{w 1}\right)-E\left(p^{0}, \widetilde{p}^{w 0}\right)\right]
$$

where changes in trade volumes are valued at the existing world price. We next use the domestic balanced trade condition in (2.1) to establish that (2.6) may be rewritten as

$$
\left[\widetilde{p}^{w 1}-\widetilde{p}^{w 0}\right] M\left(p^{1}, \widetilde{p}^{w 1}\right)=0
$$

According to (2.7), reciprocity can be given a simple and striking characterization: mutual changes in trade policy conform to the principle of reciprocity if and only if they leave the world price unchanged. With this characterization in hand, we next consider how strict adherence to reciprocity simplifies the complexity of the bargaining problem.

We examine an illustrative model. Let us take the pre-negotiation tariff pair as exogenous, with the Nash tariffs being the natural candidate. The initial tariff pair fixes a particular iso-world-price line, where as we illustrate below any such line is upward sloping in a graph with tariffs on the axes. Following Bagwell and Staiger (1999), governments simultaneously

\footnotetext{
${ }^{5}$ The adding-up constraint imposed by market clearing makes a one-for-one terms of exchange inevitable as long as governments are committed to adopting a common terms of exchange for market access applied uniformly across all governments. See Bagwell and Staiger (forthcoming) for elaboration on this point. We note also that the application of GATT's reciprocity principle in circumstances where a government modifies or withdraws a previous concession extends beyond Article XXVIII to include the case of temporary safeguard measures under GATT Article XIX and responses to nullification or impairment under GATT Article XXIII. For shorthand we continue to refer only to GATT Article XXVIII in the text.
} 
make tariff proposals, where any such proposal conforms to reciprocity and thus specifies a tariff pair $\left(\tau, \tau^{*}\right)$ that lies along the fixed iso-world-price line. If the proposals agree, then the common proposal is implemented; otherwise, the proposal with the higher tariff pair (i.e., the lowest trade volume) is implemented. This model clearly captures the reciprocal nature of tariff liberalization negotiations in GATT; in addition, the structure of the game captures in a short-hand way the potential for renegotiation under GATT Article XXVIII, since neither government can be forced to import a volume greater than implied by its proposal. ${ }^{6}$

As established by Bagwell and Staiger (1999), strict adherence to reciprocity ensures that it is a dominant strategy for each government to propose the tariff pair that if implemented would deliver its preferred trade volume along the given iso-world-price line. Indeed, once the iso-world-price line is fixed, this conclusion holds whether or not a government has private information about its preferred local price. In this sense, strict adherence to reciprocity can induce governments to truthfully reveal their politically optimal reaction curves. The key features of the argument are illustrated in Figure 1 (which is an adaptation of Figure 4 in Bagwell and Staiger, 1999). ${ }^{7}$

In the symmetric case, defined as when the Nash trade war leaves countries facing the same terms of trade as would prevail at their politically optimal tariffs, strict adherence to reciprocity leads to an efficient outcome. To develop this point, we refer to Figure 1, which depicts $\tau$ on the vertical axis and $\tau^{*}$ on the horizontal axis. The symmetric case is illustrated by the Nash point labeled $\mathrm{N}(\mathrm{C})$, which lies on the same iso-world-price locus as does the politically optimal point, which is labeled PO and lies below $\mathrm{N}(\mathrm{C})$. In Figure 1 we label as $p_{N}^{w}(C)=p_{P O}^{w}$ the iso-world-price locus passing through both $\mathrm{N}(\mathrm{C})$ and PO. As reciprocity fixes the world price, the two governments bargain along the iso-world-price locus $p_{N}^{w}(C)=p_{P O}^{w}$. The only dimension on which the governments negotiate is the volume of trade to be exchanged at the fixed world price (and trade volume is increasing as we move downward along the locus $p_{N}^{w}(C)=p_{P O}^{w}$ ).

\footnotetext{
${ }^{6}$ Under GATT Article XXVIII, if a negotiated tariff pair induces more trade volume than one government desires given the world price, then that government could raise its tariff, knowing that the other government would respond in reciprocal fashion. Our model captures this possibility in a short-hand way, by assuming that the proposal with the highest tariff pair is ultimately implemented. For more on the trade-effects interpretation of reciprocity in GATT/WTO practice in line with our discussion above, see Hoda (2001) and the Appellate Body Opinion in WTO (2004). Limao (2006, 2007) and Karacaovali and Limao (2008) provide empirical evidence that actual tariff bargaining outcomes in the GATT/WTO conform to a reciprocity norm. See also US International Chamber of Commerce (1955) for particular evidence on the importance of the reciprocity norm for the results of the Torquay Round.

${ }^{7}$ As we later discuss, with some additional structure this property implies that a researcher could invert tariff offers to estimate government preferences.
} 


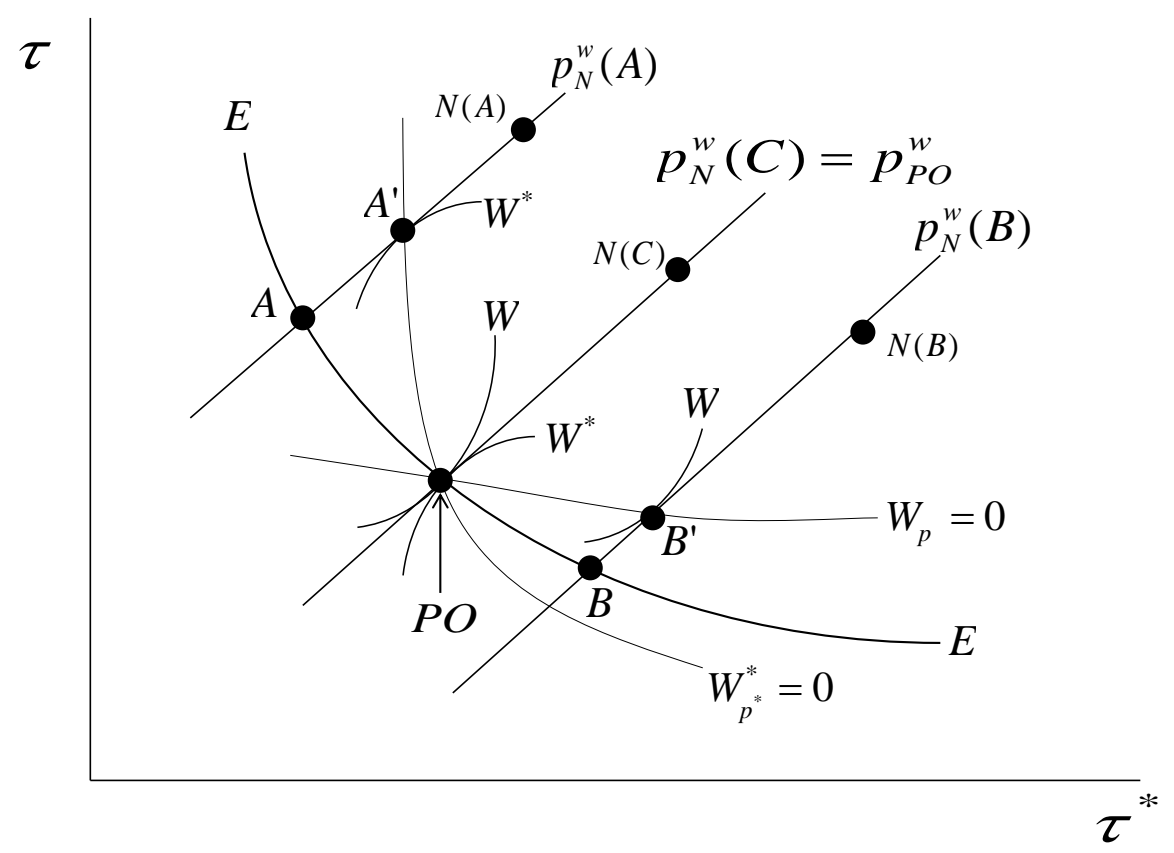

Figure 1: Reciprocity and Politcally Optimal Reaction Curves

At this fixed world price, the domestic government's desired trade volume is determined where its politically optimal reaction curve (labeled as $W_{p}=0$ ) intersects the iso-world-price locus $p_{N}^{w}(C)=p_{P O}^{w}$; and similarly the foreign government's desired trade volume is determined where its politically optimal reaction curve (labeled as $W_{p^{*}}^{*}=0$ ) intersects the iso-world-price locus $p_{N}^{w}(C)=p_{P O}^{w}$. In the symmetric case, these two points of intersection correspond to the single point which defines the political optimum (the point PO). Hence, according to Figure 1, the governments would agree on the desired volume of trade. Since it is a dominant strategy for each government in our game to propose the tariff pair that delivers its desired trade volume (i.e., to truthfully reveal its politically optimal reaction curve), it follows that the outcome of the bargaining game is the politically optimal tariff pair. Thus, in the symmetric case, strict adherence to reciprocity ensures that the bargaining outcome yields an efficient outcome corresponding to the political optimum.

Now consider an asymmetric environment. Let us begin with point N(A). As in the symmetric case, the fact that reciprocity fixes the world price implies that the two governments bargain along the iso-world-price locus passing through $\mathrm{N}(\mathrm{A})$, which we label $p_{N}^{w}(A)$. At this fixed world price, the domestic government's desired trade volume is determined where its politically optimal reaction curve $W_{p}=0$ intersects the iso-world-price locus $p_{N}^{w}(A)$; and similarly the foreign 
government's desired trade volume is determined where its politically optimal reaction curve $W_{p^{*}}^{*}=0$ intersects the iso-world-price locus $p_{N}^{w}(A)$. But the two governments no longer agree on the desired volume of trade; the foreign government's desired trade volume (labeled as $A^{\prime}$ ) is less than the desired trade volume of the domestic government (not labeled). In practice, this is where Article XXVIII comes in: any bargain that leaves the governments on a point along the iso-world-price locus $p_{N}^{w}(A)$ and which is below $A^{\prime}$ will be renegotiated at the request of the foreign government up to the point $A^{\prime}$. In terms of our game, it is a dominant strategy for each government to propose the tariff pair that delivers its desired trade volume (i.e., to truthfully reveal its politically optimal reaction curve), and so the outcome of the bargaining process is the point $A^{\prime}$. If GATT bargaining partners are asymmetric in the sense that we have described above, then the strict adherence to reciprocity that is necessary for this result will itself prevent governments from reaching the efficiency frontier (labeled $E E$ in Figure 1). ${ }^{8}$

Reciprocity with MFN We next consider MFN, and describe how reciprocity and MFN together can neutralize bargaining externalities across bargaining pairs, thereby converting a potentially complex multilateral bargaining problem into a comparatively straightforward set of bilateral bargains. To develop this point, we extend the framework of section 2.1 to a world of three countries. For this purpose we once again paraphrase the treatment in Bagwell and Staiger (2010a), and refer readers there for details.

The domestic country now exports good $y$ to two foreign countries, denoted by the superscripts ' $* 1$ ' and ' $* 2$,' and imports good $x$ from each of these countries (who do not trade with each other). Each foreign country can impose a tariff on its imports of good $y$ from the domestic country (we denote the tariff of foreign-country $i$ by $\tau^{* i}$ ), while the domestic country can set tariffs on its imports of good $x$ from the two foreign countries. If the domestic country

\footnotetext{
${ }^{8}$ Indeed, as the discussion in US International Chamber of Commerce (1955, p. 33) well illustrates, the issue of asymmetries between "high-tariff" and "low-tariff" countries was increasingly emphasized as an impediment to further negotiations with each passing GATT round. If governments have private information about their political preferences, then similar conclusions hold with respect to the ex post efficiency of bargaining outcomes, where the symmetric case then corresponds to the situation in which the pre-negotiation tariff pair lies along the same iso-welfare-price line as the ex post politically optimal tariffs. We conjecture that analogous arguments apply as well if instead the private information that governments possess concerns their levels of impatience or threat points. Throughout, we assume that governments are sufficiently patient that the negotiated tariffs satisfy self-enforcement constraints, and our conjecture is understood in this context. Finally, governments might also have private information about the form of import demand and/or export supply functions, in which case they might not agree as to the tariff pairs that satisfy the principle of reciprocity. We leave consideration of this possibility for future work.
} 
applies the tariff $\tau^{1}$ to imports from foreign-country 1 and the discriminatory tariff $\tau^{2} \neq \tau^{1}$ to imports from foreign-country 2, then separate world prices $p^{w 1}$ and $p^{w 2}$ apply to its trade with foreign-countries 1 and 2 respectively. This follows because there can only be one local price in the domestic economy, and the pricing relationships $p=\tau^{1} p^{w 1}$ and $p=\tau^{2} p^{w 2}$ then imply $p^{w 1} \neq p^{w 2}$ whenever $\tau^{1} \neq \tau^{2}$.

The MFN rule imposes a very simple requirement: the domestic country must apply a common tariff level $\tau^{1}=\tau^{2} \equiv \tau$ to the imports of $x$, regardless of whether these imports originate from foreign-country 1 or 2 . An important implication of the MFN rule is then that a single equilibrium world price, $\widetilde{p}^{w}\left(\tau, \tau^{* 1}, \tau^{* 2}\right)$, must prevail; consequently, we may continue to express government preferences with the simple representation $W\left(p, \widetilde{p}^{w}\right), W^{* 1}\left(p^{* 1}, \widetilde{p}^{w}\right)$ and $W^{* 2}\left(p^{* 2}, \widetilde{p}^{w}\right)$, where $p=\tau p^{w} \equiv p\left(\tau, p^{w}\right)$ and $p^{* i}=p^{w} / \tau^{* i} \equiv p^{* i}\left(\tau^{* i}, p^{w}\right), i=1,2$.

In a multilateral world, the MFN principle ensures that the international externality at the root of the problem to be solved by a trade agreement continues to exhibit the same structure as in the simpler 2-country setting. This suggests that, in the company of MFN, the affinity between reciprocity and truth telling described above might extend to a multilateral setting. We can show that this is indeed the case.

In addition, MFN and reciprocity together eliminate third-country spillovers from bilateral tariff bargaining. To see why, consider the case where foreign-country 2 is not involved in the negotiations and keeps its tariff unaltered. In the presence of MFN, the domestic government and the government of foreign-country 1 can still negotiate a reciprocal reduction in their tariffs $\tau$ and $\tau^{* 1}$ which leaves the terms of trade $\widetilde{p}^{w}\left(\tau, \tau^{* 1}, \tau^{* 2}\right)$ unaltered but reduces $p$ while raising $p^{* 1}$, and which therefore provides these two countries with greater trade volume. But recall now that in foreign-country 2 we have the relationship $p^{* 2}=p^{w} / \tau^{* 2}$. It follows that, with $\tau^{* 2}$ held fixed, if the negotiation between the domestic country and foreign-country 1 abides by MFN (so that a single equilibrium world price $\widetilde{p}^{w}$ prevails) and reciprocity (so that $\widetilde{p}^{w}$ is unaltered) then $p^{* 2}$ and therefore $W^{* 2}\left(p^{* 2}, \widetilde{p}^{w}\right)$ and foreign-country 2's trade volume are unaltered by these negotiations as well. In abiding by the principles of MFN and reciprocity, the domestic government and the government of foreign-country 1 have thus engineered a bilateral tariff bargain without third-country spillovers. ${ }^{9}$

\footnotetext{
${ }^{9}$ These and related points are developed in Bagwell and Staiger (2005, 2010b). An interesting question relates to the role of the "principal supplier" rule in GATT/WTO bargaining, which as we detail below directs the negotiations to emphasize the requests of the largest suppliers, if reciprocity and MFN induce the features we emphasize above. Our conjecture is that the principal supplier rule might still play two important roles
} 
Intuitively, the reciprocity principal balances two opposing third-party externalities that are present in bilateral MFN tariff bargaining: a negative externality on third parties arises when foreign country 1 cuts its tariff on imports of good $y$ in a bilateral bargain with the home country, and the externality is transmitted to competing importers of good $y$ (foreign country 2 ); at the same time, a positive third-party externality arises when the home country cuts its tariff on imports of good $x$ in a bilateral bargain with foreign country 1 and is transmitted to competing exporters of good $x$ (foreign country 2). If the home country and foreign country 1 engage in a bilateral MFN tariff bargain that cuts the tariff of foreign country 1 and the tariff of the home country in a way that just balances these two opposing third-party externalities, they can then neutralize the third-party externality of their bilateral tariff bargain. This balance is precisely what GATT's principle of reciprocity achieves in a multi-country MFN world.

In this general manner, reciprocity and MFN together can neutralize bargaining externalities across bargaining pairs, while at the same time generating dominant strategy selections for governments, thereby converting a potentially complex multilateral bargaining problem into a comparatively straightforward set of bilateral bargains. Still, as we have pointed out, if GATT bargaining partners are asymmetric, then the strict adherence to reciprocity and MFN that is necessary for these results will itself prevent governments from reaching the efficiency frontier.

Multilateral Reciprocity The preceding discussion suggests a pragmatic solution for governments to what might otherwise be an insurmountably complicated bargaining problem: endeavor to set up the GATT multilateral bargaining problem as a collection of simultaneous bilateral bargains that adhere strictly to the twin pillars of reciprocity and MFN. ${ }^{10}$ To provide further structure for our empirical analysis, we now illustrate and examine the distinction between bilateral and multilateral reciprocity. As we describe further in section 6, this dis-

in this environment: first, where strict reciprocity is not feasible - because for example the dynamic effects of tariff liberalization make it difficult to achieve reciprocity in the short run even for tariff cuts that do achieve reciprocity in the long run - and hence some spillovers become inevitable, arranging bargains in accordance with the principal-supplier rule is a natural technique for minimizing third-party spillovers; and second, even if all third-party spillovers were eliminated by a strict adherence to MFN and reciprocity, countries on the "long" side of the market for tariff cuts and who therefore face the prospect of being rationed in their ability to find enough willing bargaining partners might naturally employ the principal supplier rule to prioritize their bargaining efforts. In any case we view the development of a compelling answer to this question as an important task for future research.

${ }^{10} \mathrm{We}$ have described these results in a simple 2-good model, and it remains to demonstrate that they extend to a many-good setting of the kind that would more accurately describe the GATT bargaining environment. We believe that the key features can be extended to such environments along the lines of Bagwell and Staiger (2002, Appendix B), but this extension remains an important task for future research. 
tinction was emphasized in GATT writings at the time of the early rounds and will play an important role in our empirical analysis. After defining and illustrating multilateral reciprocity, we specify a multilateral bargaining setting and argue that each country again proposes for itself a tariff that corresponds to its politically-optimal-reaction-curve tariff when countries use dominant strategies. nrovided that tariff nronosals satisfv MFN as well as multilateteral - but

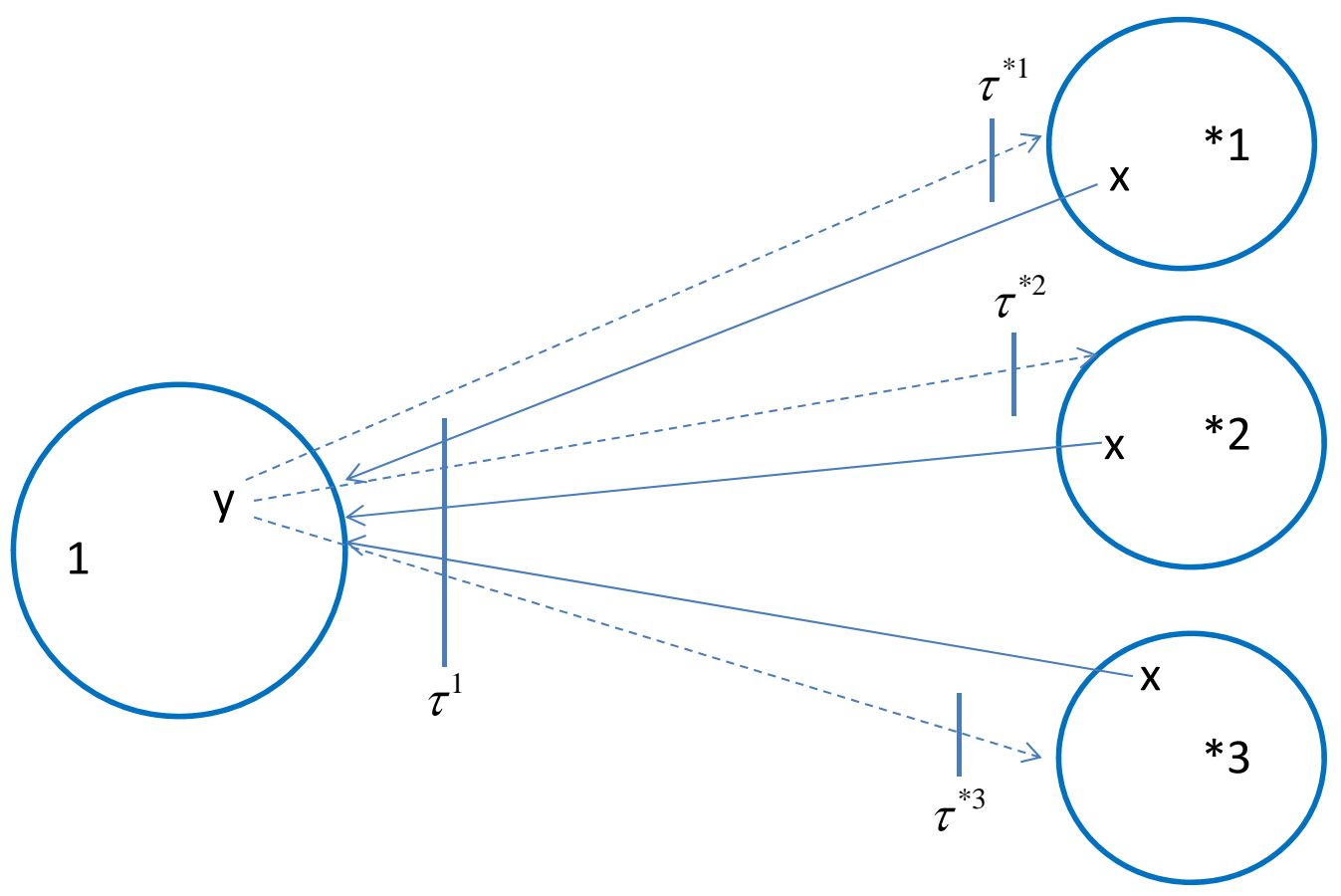

Figure 2: Multilateral Reciprocity

We begin by illustrating the distinction between bilateral and multilateral reciprocity. To this end, we consider a 4-country extension of the 2-good general equilibrium trade model described in section 2.1. Figure 2 illustrates the pattern of trade and tariff protection for the domestic country 1 and its three foreign trading partners $* 1, * 2$ and $* 3$. In line with our discussion above, we assume that the equilibrium world price is decreasing in the domestic country tariff and increasing in each of the foreign country tariffs:

$$
\widetilde{p}^{w} \equiv \widetilde{p}^{w}\left(\stackrel{(-)}{\tau^{1}}, \stackrel{(+)}{\tau^{* 1}}, \stackrel{(+)}{\tau^{* 2}}, \stackrel{(+)}{\tau^{* 3}}\right) .
$$

For purposes of illustration, we suppose that domestic country 1 is engaged in a bilateral bargain with foreign country $* 1$, and also engaged in a bilateral bargain with foreign country $* 2$, but not 
with foreign country $* 3$. Let the initial tariff vector be given as $\left(\hat{\tau}^{1}, \hat{\tau}^{* 1}, \hat{\tau}^{* 2}, \hat{\tau}^{* 3}\right)$ and suppose that, in combination with the initial tariff level $\hat{\tau}^{* 3}$, the three new tariff levels $\bar{\tau}^{1}, \bar{\tau}^{* 1}$ and $\bar{\tau}^{* 2}$ (with $\bar{\tau}^{1}<\hat{\tau}^{1}, \bar{\tau}^{* 1}<\hat{\tau}^{* 1}$ and $\bar{\tau}^{* 2}<\hat{\tau}^{* 2}$ ) would preserve the world price at its initial level, so that $\widetilde{p}^{w}\left(\bar{\tau}^{1}, \bar{\tau}^{* 1}, \bar{\tau}^{* 2}, \hat{\tau}^{* 3}\right)=\widetilde{p}^{w}\left(\hat{\tau}^{1}, \hat{\tau}^{* 1}, \hat{\tau}^{* 2}, \hat{\tau}^{* 3}\right)$.

We first illustrate a path from the initial to new tariffs that is characterized by bilateral reciprocity between domestic country 1 and each of its two bargaining partners. Suppose the domestic country starts with foreign country $* 1$ and negotiates a reciprocal deal, in which the domestic country lowers its tariff from $\hat{\tau}^{1}$ to $\tilde{\tau}^{1}$ in exchange for a reciprocal reduction in the tariff of foreign country $* 1$ from $\hat{\tau}^{* 1}$ to $\bar{\tau}^{* 1}$, where the exchange preserves the level of $\widetilde{p}^{w}$. The domestic country could then turn to foreign country $* 2$ and negotiate an additional reciprocal deal, in which the domestic country agrees to a further lowering of its tariff from $\tilde{\tau}^{1}$ to $\bar{\tau}^{1}$ in exchange for a reciprocal reduction in the tariff of foreign country $* 2$ from $\hat{\tau}^{* 2}$ to $\bar{\tau}^{* 2}$, again preserving the level of $\widetilde{p}^{w}$. Each of the just-described bilaterals satisfies reciprocity (and each therefore leaves the level of $\widetilde{p}^{w}$ unchanged), and hence the bargain described conforms to bilateral reciprocity, in the sense that the bilateral between the domestic country and foreign country $* i$ involves a reciprocal exchange of tariff cuts between the domestic country and foreign country $* i$, for $i=1,2{ }^{11}$ Notice further that, since the bilateral negotiations leave the world price unaltered, they do not affect foreign country $* 3$, and thus do not give rise to a free-rider problem.

We next consider an alternative path from the initial to new tariffs in which bilateral reciprocity fails but multilateral reciprocity holds. In its bilateral with foreign country $* 1$, suppose that the domestic country agrees to lower its tariff from $\hat{\tau}^{1}$ to $\bar{\tau}^{1}$ in exchange for a reduction in the tariff of foreign country $* 1$ from $\hat{\tau}^{* 1}$ to $\bar{\tau}^{* 1}$. The tariff changes agreed to in this bilateral would by themselves result in a rise in the level of $\widetilde{p}^{w}$, as at the existing world price foreign country $* 1$ would experience a smaller increase in the volume of its exports than the increase in the volume of its imports: these tariff changes are not bilaterally reciprocal. In its bilateral with foreign country $* 2$, suppose that the domestic country offers no further tariff cut but foreign country $* 2$ agrees to lower its tariff from $\hat{\tau}^{* 2}$ to $\bar{\tau}^{* 2}$. The tariff changes agreed to in this bilateral would by themselves result in a drop in the level of $\widetilde{p}^{w}$, as at the existing world price foreign country $* 2$ would experience a greater increase in the volume of its exports than the increase in the volume of its imports: these tariff changes are not bilaterally reciprocal either. Nev-

\footnotetext{
${ }^{11}$ Indeed, the procedure we describe here corresponds to the so-called "split concession" procedure often utilized by the US in its sequential bilateral tariff bargains under the Reciprocal Trade Agreements Act that predated GATT (see Beckett, 1941, p. 23).
} 
ertheless, taken together these two bilaterals satisfy multilateral reciprocity, as in combination they do leave the world price unaltered; that is, both foreign country $* 1$ and foreign country $* 2$ experience an equal increase in the volume of their exports and imports once each takes account of the indirect trade effects associated with the tariff changes negotiated in the other bilateral. Further, with the world price unaltered by the combination of bilaterals, a free-rider problem does not arise, as foreign country $* 3$ is again unaffected by the bilaterals.

In our Online Supplementary Notes, we examine our dominant-strategy arguments in the multi-country setting. Specifically, we assume that bilateral negotiations must satisfy MFN and multilateral reciprocity, and develop one formalization of our dominant-strategy arguments for a simple 3-country model (with one domestic country and two foreign countries). We define a game in which the three countries take as given the initial tariff vector and the accompanying world price, and then make simultaneous tariff proposals. A strategy for each country is a proposal concerning its own tariff and that of its trading partner(s), where a proposal must satisfy MFN and multilateral reciprocity (i.e., if accepted, the proposed tariffs would maintain the initial world price). Since the foreign countries do not trade with one another, a proposal from a foreign country leaves the tariff of the other foreign country at its initial value. As in the 2-country model above, each country's proposal is associated with an "implied import volume" for itself. We then construct a simple mechanism that takes the three proposals and assigns a vector of tariffs. The domestic country's proposal is assigned if the proposals agree. ${ }^{12}$ If the proposals do not agree, we require that the constructed mechanism assigns a vector of tariffs that maximizes the value of trade volume subject to maintaining the initial world price and not forcing any country to import a volume in excess of its implied import volume. ${ }^{13}$

\footnotetext{
${ }^{12}$ Agreement is defined to mean that, for any foreign country $* i$, the domestic country and foreign country $* i$ make the same proposal as regards foreign country $* i$ 's tariff while foreign country $* i$ is indifferent between its own proposal and the domestic-country proposal as regards the tariffs for the domestic country and foreign country $* j, j \neq i$.

${ }^{13}$ This requirement delivers a unique tariff vector assignment when the value of the domestic country's implied import volume weakly exceeds the aggregate value of the foreign countries' implied import volumes. If the domestic country is on the "short" side, rationing occurs, and our requirement does not result in a unique tariff vector assignment. For this case, we construct the mechanism so that it randomly selects one foreign country to have first priority. The constructed mechanism assigns tariffs such that the prioritized foreign country imports a volume equal to the minimum of its implied import volume and the value of the domestic country's implied import volume, while the other foreign country imports a volume equal to the difference between the value of the domestic country's implied import volume and the prioritized foreign country's implied import volume (if that difference is positive). Similar results would obtain under other prioritization rules, including rules that give priority to a principal supplier, provided that priority is not influenced by foreign proposals (conditional on being in the case where the domestic country is short).
} 
For the constructed mechanism, if countries use dominant strategies, we show that each country's proposal must specify a tariff for itself that delivers its preferred trade volume, given the initial world price. As our 4-country illustration above suggests, a novel feature of the multi-country setting is that the domestic country now has a set of dominant strategies. This set is defined by proposals under which the domestic country proposes for itself the tariff that delivers its preferred trade volume given the world price and proposes for the foreign countries any tariffs that when combined with the domestic tariff maintain the world price and thus ensure multilateral reciprocity. Importantly, the set of dominant strategies for the domestic country allows that its proposed tariff for itself may violate bilateral reciprocity when paired with its proposed tariff for an individual foreign country. And finally, as in the two-country model, we note that once the world price is fixed, dominant strategy proposals are similarly characterized even when governments have private information about their respective preferences.

The basic arguments apply as well in a 4-country setting, where country $* 3$ does not participate in the negotiations. In this context, when negotiations must satisfy MFN and multilateral reciprocity, (i) if countries $1, * 1$ and $* 2$ use dominant strategies, then each of these countries makes a proposal that specifies its politically-optimal-reaction-curve tariff for itself, and (ii) foreign country $* 3$ will be unaffected by the bilaterals (and there can be no free rider problems as a result). As before, under dominant strategy proposals, the implemented tariff vector is again efficient if and only if the initial world price is set at the politically optimal level.

\section{The GATT Bargaining Protocols}

The first five GATT rounds adopted selective product-by-product tariff negotiations on a bilateral request-offer basis, as did the eighth (Uruguay) and to varying degrees the present (Doha) round. As Hoda (2001) explains, the protocols for the first five rounds were broadly similar:

Each round began with the adoption of a decision convening a tariff conference on a fixed future date. The decision required the contracting parties to exchange request lists and furnish the latest edition of their customs tariffs and their foreign trade statistics for a recent period well in advance of the first day of the conference and the offers had to be made on the first day. The negotiations were concluded generally over a period of six to seven months after the offers had been made...These negotiations were essentially bilateral between pairs of delegations. (pp. 44-45) 
As a general matter, the initial request lists of tariff cuts were common knowledge (circulated among all of the participating governments) in each of the first five rounds, while the backand-forth offers and counteroffers that transpired within each bilateral were known only to the participating governments in that bilateral, until the GATT Secretariat was informed that an outcome for that bilateral (success or failure) had been achieved, at which point the details of the outcome became common knowledge. Tariffs agreed in a bilateral would apply on a nondiscriminatory basis to exports from any GATT-member country through the MFN principle.

General Objectives and the Nature of Negotiations The protocols all included a statement of general objectives ("...to bring about the substantial reduction of tariffs and the elimination of tariff preferences"), and a description of the general nature of negotiations which placed emphasis on achieving balance in the negotiations and flexibility to maintain tariffs at individually preferred levels. For example, the protocol for the initial 1947 GATT round in Geneva stated that

...tariff negotiations shall be on a 'reciprocal' and 'mutually advantageous' basis. This means that no country would be expected to grant concessions unilaterally, without action by others, or to grant concessions to others which are not adequately counterbalanced by concessions in return

The elimination of tariff preferences (mainly those of the British Commonwealth system, which were often product specific and reflected a grant of market access at preferential but not necessarily zero tariff rates) was also emphasized in the early GATT protocols; and it was anticipated that negotiated reductions in MFN tariffs would be the main engine for achieving this goal, as reflected for example in the statement from the protocol for the initial 1947 GATT round in Geneva that

All negotiated reductions in most-favored-nation import tariffs shall operate automatically to reduce or eliminate margins of preference.

A Base Date for Preference Standstill and Avoidance of New Tariffs It was agreed that no margin of tariff preference should be increased as a result of GATT negotiations, and to implement this agreement a base date for the calculations of the preference margins existing prior to the first GATT negotiating round had to be set. In addition, in order to avoid the 
problem of "bargaining tariffs" raised on the eve of a round for bargaining purposes, each protocol contained rules against such conduct.

Principal Supplier Rule All protocols envisaged that the selective product-by-product tariff negotiations would proceed according to the "principal supplier" rule. In the protocol for the initial 1947 GATT round in Geneva which was held among 23 member countries of the (Havana Charter) Preparatory Committee, the principal supplier rule was defined:

It is generally agreed that the negotiations should proceed on the basis of the "principal supplier' rule, as defined in this paragraph. This means that each country would be expected to consider the granting of tariff or preference concessions only on products of which the other members of the Preparatory Committee, are, or are likely to be, principal suppliers... In other words, if a principal part of total imports of a particular product into the territory of a particular member is supplied by the other members of the Preparatory Committee taken together, then the importing member should, as a general rule, be willing to include that product in the negotiations, even though no single other member of the Committee, taken by itself, supplies a principal part of the total imports of the product.

Extensive Form of Negotiations The protocols described procedures for conducting negotiations which amounted to a four stage process. At a broad level, these procedures were described in greatest detail in the protocol for the initial 1947 GATT round in Geneva, though as we explain further below there was some evolution in particular features of these procedures across rounds. The protocol for the 1947 round stipulated the following timing:

1. Prior to the opening of talks, each participating country transmits a list of requests of concessions it seeks at the product level.

2. At the opening of talks, each country submits a list of concessions it would offer given the requests it has made of others.

3. Pairs of countries negotiate directly over concessions of primary concern between those two countries. This is effectively simultaneous interconnected bargaining.

4. As bilateral agreements are reached, third party countries can examine the agreements, and potentially modify their agreements in response. 
Later rounds evolved along several specific dimensions. In particular, the rules on sharing the information among participants about initial offers (the second stage of the 1947 protocol) evolved somewhat from round to round. For example, the protocol for the 1949 Annecy Round states:

...On 11 April, 1949, - that is, on the first day of the meeting..., each government will make known to all participating governments the concessions which it is prepared to offer to each government from which a request for concessions was received... When the concessions offered by all participating governments have been exchanged and distributed, negotiations between pairs of delegations will begin.

Here it seems clear that the initial offers, like the initial requests, were to be common knowledge. But by the 1950-51 Torquay Round, the emphasis on sharing initial (second stage) offers among participants seems to have disappeared. The Torquay protocol states:

On September 28, 1950 - that is, on the first day of the meeting in Torquay - each government should be ready to make known the concessions it is prepared to offer to each government from which a request for concessions is received... When the offers have been exchanged, negotiations between pairs of delegations will begin.

\section{The GATT Bargaining Records}

The GATT bargaining records make it possible to recover the complete history of offers and counteroffers in a given round. For the Torquay Round, we illustrate in Figure 3 with a sample of the bargaining record from the US-France bilateral negotiation from that round.

This particular bilateral began on February 61951 with an exchange of secret offers (not shown in Figure 3) between France and the US describing the tariff cuts to which each would agree if the other met its earlier (and publicly) announced requests. The excerpted bargaining record in Figure 3 describes a portion of the (secret) request by the US on February 24 that France supplement its February-6 offer. France did supplement its offer on March 31 1951, and on that day the US and France announced publicly the agreement resulting from their bilateral (which amounted to the US tariff cuts offered to France on February 6 and the supplemented France tariff cuts offered to the US on March 31). By following in this way the timing and sequence of the request-offer records, we can construct the full sequence of offers and counteroffers that led to agreement or disagreement for each of the bilaterals in the Torquay round. 


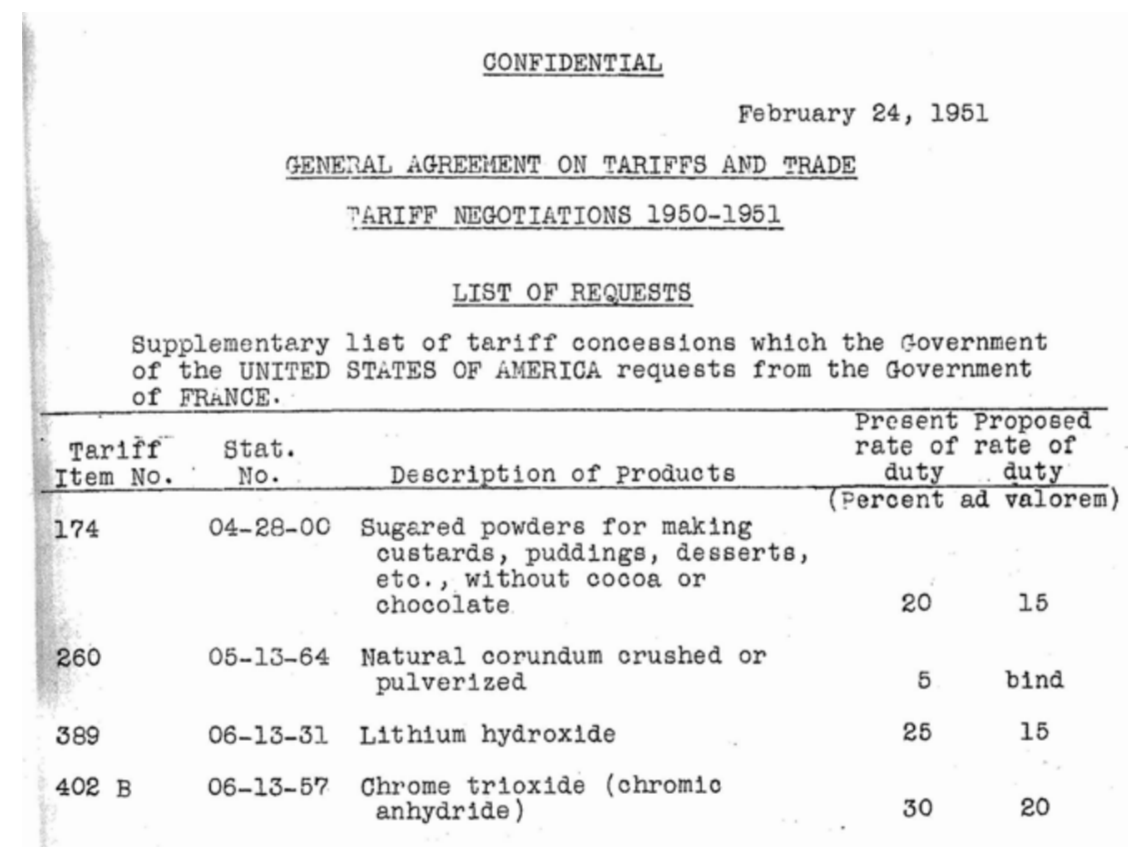

Figure 3: Excerpt of US-France Negotiation Record

To illustrate further how the GATT bargaining records can be used to illuminate the multilateral bargaining behavior of participants in the Round, we highlight in Figure 4 the bargaining behavior of the US with regard to one particular 6-digit product, HS 843319 (Mowers for lawns, other than powered and with a horizontal rotating cutter). Specifically, Figure 4 depicts the complete request-offer sequence involving the tariffs on such lawn mowers between the US and each of the five countries whose bilateral bargains with the US involved a request and/or offer on this product. We denote by the symbol $\mathrm{R}$ a request, by $\mathrm{O}$ an offer, by $\mathrm{OW}$ a withdrawn offer and by A an agreement. These symbols are positioned at the height of the tariff request or offer, so that a horizontal line between any two symbols indicates that the tariff level across those two actions is the same, while an upward sloping (downward sloping) line between any two symbols indicates that the tariff level across those two actions increased (decreased).

As reflected in Figure 4, between June 1 and July 1, 1950, the US made requests of all five of these countries (Canada, New Zealand, Peru, Sweden and the UK) to reduce their import tariffs on such lawn mowers, and the US received requests to reduce its own tariff on these lawn mowers from two of the countries (Canada and the UK). In the months that followed, Peru and Sweden each made offers to the US at a level which met the US request, while New Zealand, Canada and the UK each made offers to the US at a level which did not go all the way to meet 
the US request and New Zealand and the UK subsequently withdrew their offers; and for its part, the US did not respond to the Canadian request but did make an offer to the UK to cut its tariff on this product, an offer that the US subsequently withdrew. The final commitments on HS 843319 tariffs emerging from these five bilaterals were three: a commitment by Canada negotiated with the US to reduce the Canadian tariff on lawn mowers; a commitment by Peru negotiated with the US to reduce the Peruvian tariff on lawn mowers; and a commitment by Sweden negotiated with the US to reduce the Swedish tariff on lawn mowers.

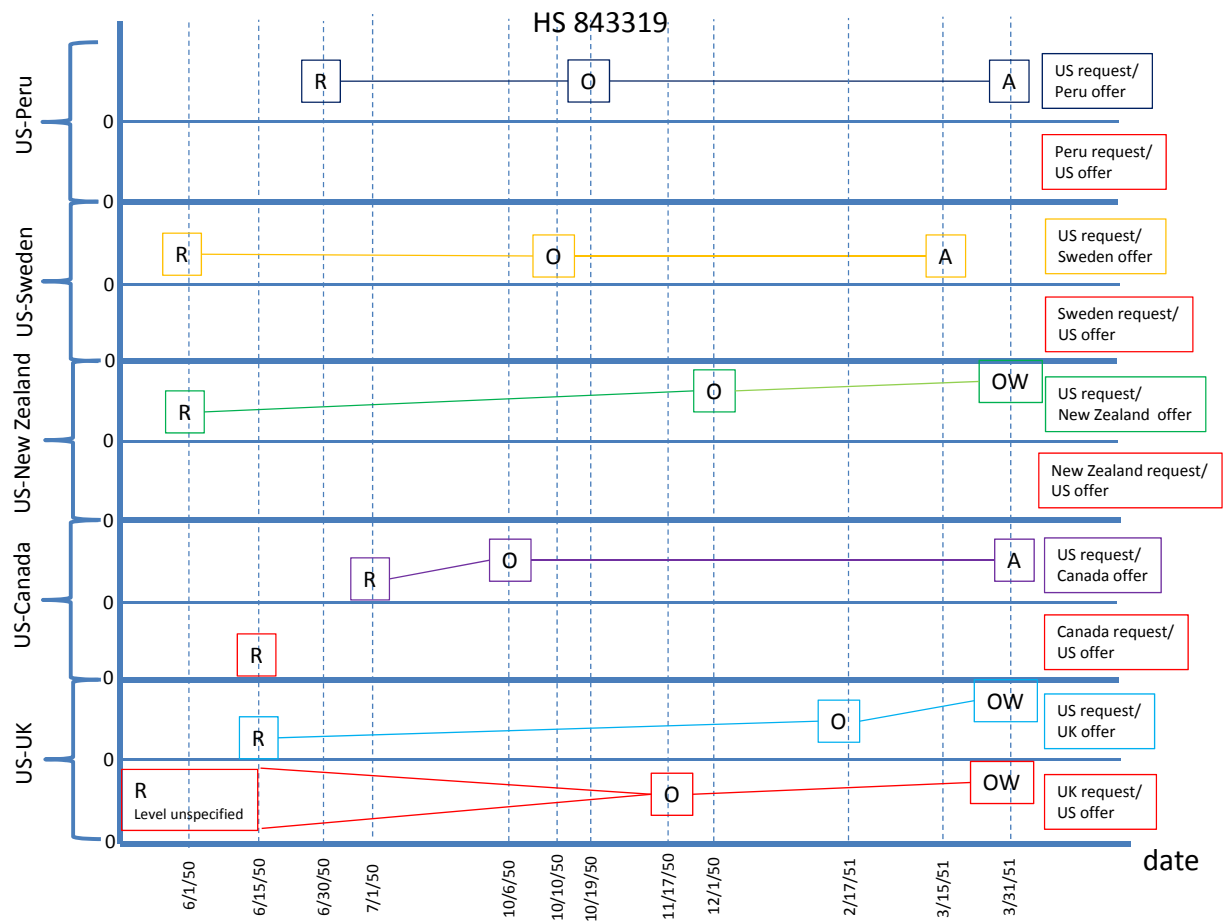

Figure 4: Requests and Offers on Lawn Mowers in US Torquay Bilaterals.

Notes: This Figure depicts the complete request-offer sequence between the US and each of the five countries whose bilateral bargains with the US involved a request and/or offer on lawn mowers (HS 843319). The symbol $\mathrm{R}$ denotes a request, $\mathrm{O}$ an offer, $\mathrm{OW}$ a withdrawn offer and $\mathrm{A}$ an agreement. These symbols are positioned at the height of the tariff request or offer, so that a horizontal (upward/downward sloping) line between any two symbols indicates that the tariff level across those two actions is the same (increased/decreased).

A critical question is the degree to which the GATT bargaining records provide a complete catalog of every offer and counteroffer that was tendered in a round. If they do not, then there is still valuable information in the recorded bargaining outcomes in the sense that not only 
successful bargains but also bargaining failure can be observed, but the official record of offers and counteroffers is less likely to be an informative object of study.

While it would be implausible to suppose that there was no communication outside of the formal offers and counteroffers recorded in the GATT bargaining records, at least for the earlier rounds there is reason to believe that the records offer a fairly complete catalog of the tendered offers and counteroffers. ${ }^{14}$ This is so for two reasons. First, in older rounds such as the Torquay Round that predated the ready use of electronic records and portable computing devices, a written record of the detailed product-level bilateral tariff cutting proposals - proposals which typically included dozens if not hundreds of product-level tariff cuts to be considered - was the only way that a proposal or counter-proposal could be offered and assessed. ${ }^{15}$ Second, the final bargaining outcomes in the GATT bargaining records predominantly emerge in a continuous fashion from the recorded requests, offers and counteroffers, rather than appearing in the final agreement as a new and never-before-recorded proposal - for example, over $95 \%$ of the exact tariff bindings to which the US ultimately agreed in the Torquay Round first appear in the USTorquay bargaining records as either requests by US bargaining partners or as earlier US offers to some bargaining partner - which is at least consistent with the lack of important informal proposals being tendered outside of the recorded offers and counteroffers. ${ }^{16}$

There are a number of significant challenges that must be overcome before the GATT bargaining data can be used for research. The Online Data Appendix covers these issues in detail. The most challenging issue concerned creating product level concordances across negotiations. Our solution was to concord product level descriptions into HS 1988 6-digit codes. We henceforth refer to an HS6 code as a product.

\footnotetext{
${ }^{14}$ In fact, we can document one example of explicit communication that occurred outside of the GATT Torquay bargaining records. In a secret cable from the head of the UK delegation to the head of the US delegation at Torquay on March 141951 (see US State Department, 1951a), the UK presented the US with a revised request list. However, this example also seems to acknowledge the non-routine nature of the action with the following statement made by the head of the UK delegation: "I should be glad if you would consider this list as a revised request list in what one would have to regard as changed circumstances...".

${ }^{15}$ We thank Sushan Demirjian, Deputy Assistant USTR for Market Access and Industrial Competitiveness, for pointing this out to us.

${ }^{16}$ More specifically, only 44 out of the 988 tariff bindings to which the US agreed in its Torquay bilaterals do not appear as either requests or earlier offers in some US bilateral; and this count reflects an upper bound, because the numbers are calculated at the HS6 level and a lack of match could (and does in each of the cases we have checked) reflect changes in the 10 digit product mix in any given HS6 product category over the course of the bargain rather than the appearance of a tariff binding in the final agreement that did not appear somewhere in the US bilateral bargaining records at an earlier date. That said, this statistic may be less informative regarding the completeness of the bargaining records than it first appears, because as we discuss below there is very little intensive-margin movement in the offers through time.
} 


\section{Stylized Facts of GATT Tariff Bargaining}

We now use data from the US bilaterals at Torquay to develop a number of stylized facts relating to GATT tariff bargaining. While our subsequent data analysis in part helps to provide possible interpretations for some of these stylized facts, our main purpose here is simply to identify the facts. We start with an overview of the number of parties and the timing and frequency of offers. We then state a set of stylized facts, focusing first on bargaining patterns alone and then introducing trade data and expanding our focus to bargaining and trade patterns.

\subsection{Overview}

We begin with a helicopter view of the US-Torquay negotiations. There were 39 participating countries in the Torquay Round, accounting for well over 80 percent of world trade as of 1949 (see, for example, US Department of State, 1951b, p. 1). ${ }^{17}$ However, the Benelux customs union (consisting of Belgium, Luxembourg and the Netherlands) negotiated its common external tariffs as a single entity, reducing the total number of parties negotiating at Torquay to 37. Of the 666 possible bilaterals, 588 were initiated. The US was engaged in bilateral negotiations with 24 of its 36 potential negotiating partners (i.e., the US made initial requests of and/or received initial requests from 24 of these countries). ${ }^{18}$ It reached final agreement with 15.

In Figure 5 we provide an overview of the timing and actions - request $(\mathrm{R})$, modification of request (RM), offer $(\mathrm{O})$, modification of offer $(\mathrm{OM})$, withdrawal of offer $(\mathrm{OW})$, agreement (A) and modification of agreement (AM) - for each of the 24 bilateral negotiations involving the US at Torquay. The dates of each action are recorded on the horizontal axis. For each US negotiating partner listed on the vertical axis, the bottom (blue) line displays the actions relating to the US tariff - the offers by the US and the requests of its negotiating partners while the top (red) line displays the actions relating to the foreign negotiating partner's tariff - the requests by the US and the offers of its negotiating partners. Figure 5 displays 57 dates, distributed across the 10 month period of the Torquay Round, on which the US and/or at least

\footnotetext{
${ }^{17}$ The countries were Australia, Austria, Benelux Countries - Belgium, Luxembourg, Netherlands, Brazil, Burma, Canada, Ceylon, Chile, Cuba, Czechoslovakia, Denmark, Dominican Republic, Finland, France, Germany, Greece, Guatemala, Haiti, India, Indonesia, Italy, Korea, Liberia, New Zealand, Nicaragua, Norway, Pakistan, Peru, Philippines, Southern Rhodesia, Sweden, Syria-Lebanon, Turkey, South Africa, United Kingdom, United States and Uruguay. Of these, six were negotiating for accession at Torquay: Austria, Germany, Korea, Peru, Philippines and Turkey.

${ }^{18}$ The countries present at Torquay with which the US did not negotiate were Burma, Ceylon, Chile, Finland, Greece, Liberia, Nicaragua, Pakistan, Philippines, Southern Rhodesia, Syria-Lebanon and Uruguay.
} 


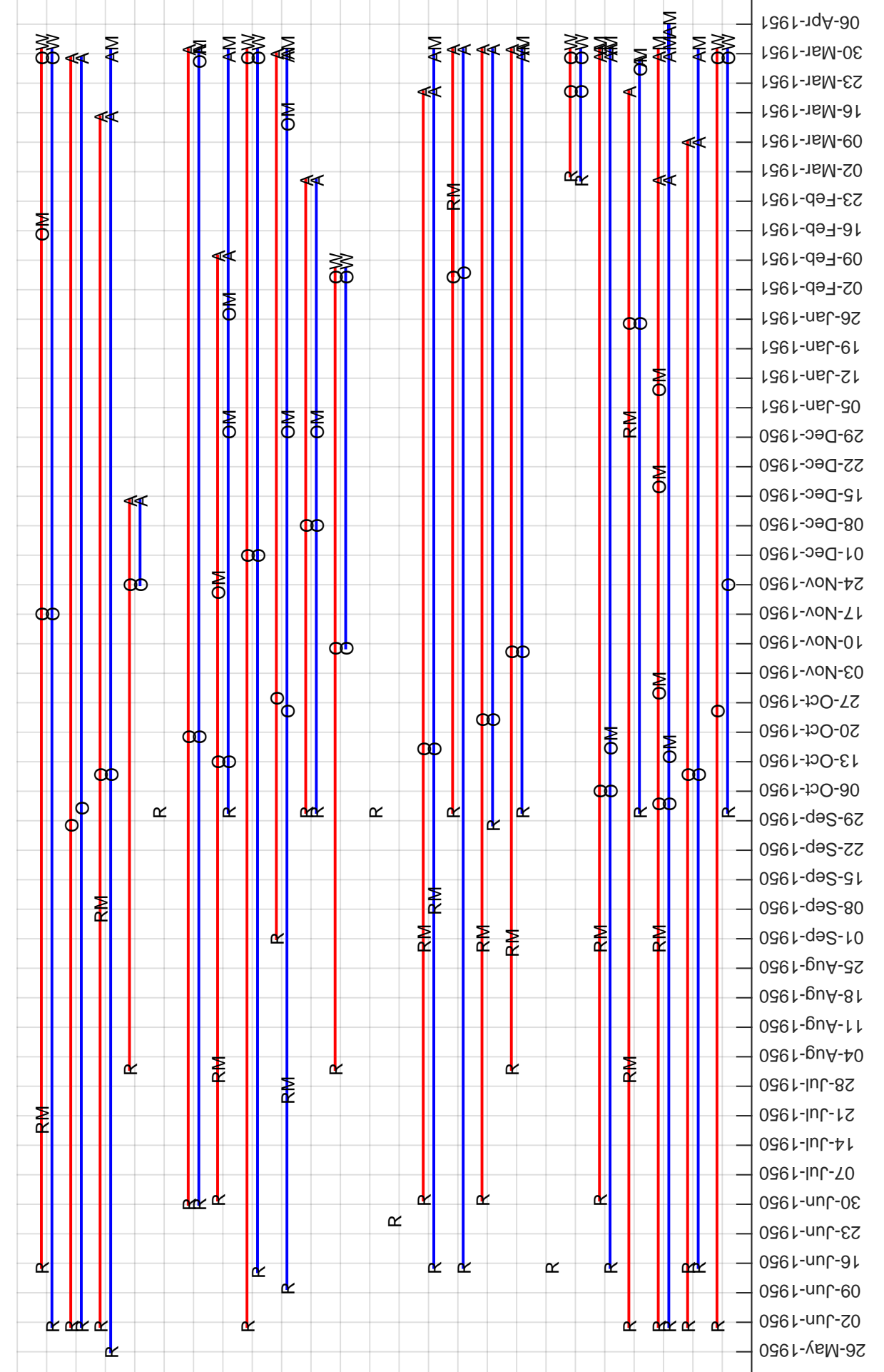

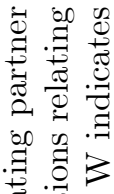

类

$\stackrel{ }{Ð}$

os

궁

$\approx=5$

ठै.

I.

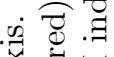

政

풍 क्षे

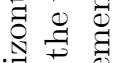

范范

$8 \%$

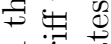

ธี ฐี

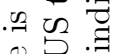

:

EF

$\ddot{0}$ 요원

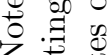

4 要

is

శึ.

范

जी

o

胥

하유

E

吸 $\Xi$

叫

要

.

दै $\overrightarrow{0}$

웅

艺

4.50

西

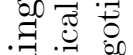

छق

F 80

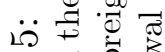

○ 둥

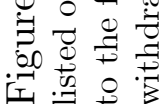


one of its negotiating partners took an action in their bilateral. As Figure 5 illustrates, most of the dates involve multiple actions across a number of bilaterals.

\subsection{Stylized Facts: Bargaining Patterns}

We now record and document six stylized facts relating to GATT bargaining patterns.

Stylized Fact 1: The numbers of back-and-forth offers and counter-offers in any bilateral bargain are relatively small, and for some bargains the initial offers sit dormant on the table for long periods of time and are then finalized with a single modification at the time that other bargains are concluded.

While the US and/or its negotiating partners took actions on 57 separate dates before reaching a conclusion to the Round, Figure 5 reveals that the amount of "back-and-forth" within any bilateral is much more limited, often consisting of only a couple of actions by each party over the course of the Round and never more than a handful by either. In Tables 1 and 2 we present specific evidence on the amount of back-and-forth offers and counter-offers during negotiations, with Table 1 focused on US sales (i.e., for requests and offers that refer to US tariffs) and Table 2 focused on US purchases (i.e., for requests and offers that refer to the tariffs of US bargaining partners). As Table 1 shows, on HS6 products for which the US made at least one offer in the bilateral, the maximum number of offers it made on that product is 3 and the average is 1.6; for requests the analogous numbers are 2 and $1 .{ }^{19}$ Conditional on a final agreement reached on that HS6 product in that bilateral, the maximum number of offers the US made on that product is again 3 but the average is now 2; and for requests the analogous numbers are still 2 and 1. Table 1 also reports the data on the simple counts of US offers and counter-offers for a country pair (but not also per good). For bilaterals where the US made at least one offer, the average number of US offers per bilateral is 2.6, with a maximum number of 5 , and conditional on a final agreement reached between the two countries in that bilateral the analogous numbers are 3.1 and 5. And the analogous numbers of US requests for a country pair are an average of 1.2 and a maximum of 3 independently of whether or not a final agreement is reached. Table 2 shows the analogous information for the requests and offers that refer to the tariffs of US bargaining partners, and depicts broadly similar patterns. Models of strategic

\footnotetext{
${ }^{19}$ For example, a product might be included in an initial offer, and then also be in the set of products that is included in a modified offer, and then later the offer on this product might be withdrawn, in which case we would record that a total of 3 offers were made on this product.
} 
delay in bargaining (e.g., Admati and Perry, 1987, and Cramton, 1992) predict small numbers of offers and counter-offers broadly in line with our findings here, though these models cannot be applied directly to settings of bilateral bargaining with externalities. ${ }^{20}$

Figure 5 also reveals that some bilateral bargains sit dormant for long periods of time and yet ultimately end in agreement. For example, Figure 5 shows that the US and Denmark exchanged initial offers on 11/8/1950, made no modifications to their requests of or offers to each other after that date, and reached a final agreement on 3/31/1951. A possible interpretation is that the initial proposals contained the elements of a final agreement, but the details of the final agreement hinged on details of other bilaterals that had yet to be concluded. Relatedly, a number of the initial offers were not tabled until midway through the round, possibly reflecting issues of sequencing across bilaterals. These features suggest multilateral linkages across the bilateral bargains. ${ }^{21}$ Finally, there are a number of agreements that are themselves modified late in the round $(\mathrm{AM})$. One interpretation of these modifications is that they reflect the kinds of adjustments that stage- 4 of the Torquay Protocol anticipated might be necessary as information became available about other agreements that were concluded in the round. Together these patterns point to important multilateral dimensions of the bargaining, whereby large numbers of separate bilateral bargains, each with small numbers of moves, were linked together into an interrelated fabric. We will later offer evidence that countries sought multilateral reciprocity in their negotiations, which would introduce an important multilateral dimension into each country's bargaining and therefore be consistent with this interpretation.

Stylized Fact 2: While in principle a proposal can be altered by either modifying the tariff commitment requested of one's bargaining partner or modifying the own-tariff commitment offered to the bargaining partner, in practice the mechanics of altering proposals through time overwhelmingly takes the form of modifications to offers rather than modifications of requests.

An additional interesting pattern revealed by Figure 5 is that, once initial offers had been exchanged and the bilateral bargaining stage of the Torquay Round began, virtually all the

\footnotetext{
${ }^{20}$ While we do not attempt structural estimation of a bargaining model in this paper, it is nevertheless useful to point out that the mechanism characterized in our Online Supplementary Notes can generate equilibrium outcomes consistent with no offer adjustments (when countries are symmetric) or one offer adjustment (when countries are asymmetric), and two or more offer adjustments in the presence of shocks (e.g., a given bilateral randomly fails) that require countries to switch to other strategies within their sets of dominant strategies.

${ }^{21}$ Indeed, the importance of such linkages for understanding the pattern of bargaining at Torquay was emphasized in various accounts at the time. For example, in its October 2 coverage of the opening of the Torquay Round negotiations, The New York Times (1950a) observed: "There is always a tendency in these meetings for delegations to delay negotiations until they get some inkling as to how bigger ones are going..."
} 
back-and-forth occurs on offers rather than requests. That is, countries choose overwhelmingly (in fact, with only one exception) to make counter-proposals by modifying their own-tariff-cut offers rather than modifying the tariff-cut requests they make of their bargaining partners. This pattern warrants future study, but one possibility is again that it may reflect important multilateral dimensions of the bargaining. For example, if a country is attempting to achieve a balance in its bilaterals that is consistent with multilateral reciprocity, it is likely to be more straightforward for the country to modify its own offers in order to achieve this balance than to attempt to achieve balance by requesting modifications to its bargaining partners' offers, because the ramifications of such requests for the bargaining partners with regard to their other bilaterals are likely to be unknown to the country making these requests. We note as well that the lack of modified requests of a bargaining partner is consistent with our earlier observation that, in light of GATT Article XXVIII, it is pointless to attempt to force a bargaining partner to import a volume greater than implied by the bargaining partner's proposal. ${ }^{22}$

Stylized Fact 3: While the set of requests a country entertains seems to conform with what might be expected on the basis of the principal supplier rule, when it comes to deciding which bargaining partners to make requests of on a given product there appears to be a more narrow focus than principal supplier considerations alone would dictate.

Table 3 details the number of HS6 level product categories involved in negotiations for US tariff cuts ("sales," in the top panel) and negotiating partner tariff cuts ("purchases," in the bottom panel). The first column reports the number of HS6 products across all negotiating partners, the second column reports the number of HS6 product-negotiating partner pairs, and the third through sixth columns report summary statistics by negotiating partner on the number of HS6 products.

We may conclude from the first and third rows of the top panel in Table 3 that on average the requests received by the US and the offers made by the US reflect a high degree of concentration across exporting countries, with somewhere between 1 and 2 exporting countries typically bargaining with the US over a given US tariff reduction. Under the assumption (which

\footnotetext{
${ }^{22}$ As we observed earlier (see note 14), we have also documented a case (US State Department, 1951a) in which the UK issued a revised request list to the US during the bilateral bargaining stage in a secret cable that is not contained in the GATT Torquay bargaining records. However, in its request modifications the UK did not ask the US for greater market access concessions than the US had offered; instead, the US was preparing to scale back its previous offers to match the disappointing offers it had earlier received from the UK, and in the words of the US delegation as quoted in note 3 of the cable, the revised request list was "clearly intended to inform us that the U.K. did not want a limited agreement without [these] controversial items."
} 
we will confirm below with the US import data) that the larger export suppliers of a product into a market are the suppliers usually involved in the bargaining over access to the market for that product, this in turn implies that typically it is the largest 1 or 2 export suppliers into the US market on a given product that are engaged in negotiations over the US tariff in that market, consistent with the principal supplier rule. But the bottom panel of Table 3 seems to tell a different story. The US was one of the largest trading economies of the day, and while product-level by-country export data for the period is not currently available, it seems likely that, when the US was among the largest export suppliers of a product into one country, it would have enjoyed similar status for that product in the markets of many countries. ${ }^{23}$ And yet, the first and third rows of the bottom panel in Table 3 indicate that on average the US singled out just a couple of countries in its Torquay bargaining attempts to lower foreign tariffs on any given product. It therefore appears that something beyond principal supplier status is limiting the cross-country scope of US bargaining efforts at Torquay.

Table 4 provides further evidence on this point. This table shows that, for both US sales (i.e., for requests and offers that refer to US tariffs) and US purchases (i.e., for requests and offers that refer to the tariffs of US bargaining partners), the modal HS6 level product category was under negotiation with only one partner. At the same time, Table 4 indicates that a significant number of HS6 level product categories were at play with multiple numbers of negotiating partners, indicating important direct linkages across negotiations. In particular, the left panel indicates that, of the HS6 products on which the US received a request, it received a request from only one trading partner on $57 \%$ of these products but received requests from more than three trading partners on only $7 \%$ of these products. Similarly, of the HS6 products on which the US made an offer, it made the offer to only one trading partner on $65 \%$ of these products but made the offer to more than three trading partners on only $4 \%$ of these products, with the corresponding percentages for successful offers being $78 \%$ and $1 \%$ respectively. Turning to the right panel of Table 4 we see that, of the HS6 products on which the US made a request, it made its request of only one trading partner on $51 \%$ of these products and made requests from more than three trading partners on $17 \%$ of these products. Similarly, of the HS6 products on which the US received an offer, it received the offer from only one trading partner on $54 \%$ of these products and received an offer from more than three trading partners on $14 \%$ of these products,

\footnotetext{
${ }^{23}$ While we have the relevant trade data in electronic form, the necessary concordances have yet to be created. This is a major undertaking, and it is the focus of ongoing work.
} 
with the corresponding percentages for successful offers being $64 \%$ and $5 \%$ respectively.

There is a rightward shift of the distribution between the left and right panels of Table 4 as would be expected for a large country such as the US that is likely to be the principal supplier of products into multiple foreign markets. But what is surprising is how small this rightward shift is, again indicating that something beyond principal supplier status seems to be limiting the cross-country scope of US bargaining efforts at Torquay. An interesting question, which we leave for future research, is whether strategic elements in the GATT tariff bargaining environment could account for this.

Stylized Fact 4: Substantial numbers of offers are made that were not requested by the country to which the offer is extended. In significant numbers of cases, these offers are made without a request from any bargaining partner.

Again from Table 3, while the US entertained requests for tariff cuts on 2,586 HS6 products, it offered tariff cuts on 1,769 HS6 products, 1,357 of which correspond to HS6 products that were requested by some bargaining partner, and 412 of which correspond to products that were not requested by any bargaining partner. And while the US requested tariff cuts from its bargaining partners on 2,298 HS6 products, it received offers on 1,844 HS6 products, 1,595 of which corresponded to HS6 products that it had requested, and 249 of which corresponded to HS6 products that it had not requested. Moreover, of the 2,635 initial offers that the US made across its bargaining partners, 1,107 of these were made to bargaining partners on HS6 products which they themselves had requested, while the remaining 1,528 of these were made to bargaining partners on HS6 products that they themselves had not requested; by contrast, of the 3,665 initial offers that the US received from its bargaining partners, 2,793 of these were received from bargaining partners that were responding to a US request on this HS6 product, while the remaining 872 of these were received from bargaining partners that had not received a US request on this HS6 product.

In the end, as Table 3 reveals, the US agreed to final concessions on 1,260 of the 1,769 HS6 products that it had offered, while its bargaining partners agreed to final concessions in their bilaterals with the US on 1,505 of the 1,844 HS6 products that they had offered the US. Most, but not all, products that reached a final agreement were initially requested: $23.7 \%$ of the agreed US tariff cuts were on HS6 products that were not requested by its negotiating partners, while $13.5 \%$ of the tariff cuts agreed to by US negotiating partners in their bilaterals with the US were on HS6 products that were not requested by the US. 
Stylized Fact 5: The bargaining appears to have taken the form of essentially take-or-leave offers on the intensive margin (the level of the tariff cut offered) and back-and-forth offers and counter-offers on the extensive margin (which products are to be included in the bargain).

Table 5 describes the magnitude of the tariff concessions requested and offered for US "sales" (i.e., for requests and offers that refer to US tariffs) and US "purchases" (i.e., for requests and offers that refer to the tariffs of US bargaining partners). This table reports statistics by HS code - country pair; and it conditions on finalized agreed concessions being reached. As the top row reveals, the average tariff cut requested from the US by its bargaining partners amounted to roughly a $40 \%$ cut in the existing (ad valorem and specific) US tariff, while the average tariff cut requested by the US of its bargaining partners amounted to approximately a $30 \%$ cut in their existing (ad valorem and specific) tariff level. The bottom rows show that the tariff cuts that the US actually agreed to amounted to on average a $32 \%$ cut in its existing tariff, whereas the tariff cuts that the US was able to convince its bargaining partners to agree to amounted to on average roughly an $11 \%$ cut in their existing tariff.

The middle three rows of Table 5 reveal that the levels of the initial offers in effect determined the levels of the finalized concessions. For both US sales and US purchases, these averages reveal an apparent lack of adjustment along the intensive margin between the initial offers and the finalized concessions. In Table 6 we provide additional evidence that changes on the intensive margin were small in magnitude. Unlike Table 5, Table 6 reports statistics by HS code but does not condition on country pair; and it does not condition on finalized concessions being reached. As Table 6 reflects, for US sales the average final offer was very close to the initial offer (US purchases in Table 6 reflect movements across US bargaining partners, and so are not informative about this feature). ${ }^{24}$ Finally, we return to Table 3 and now focus on the fourth row,

\footnotetext{
${ }^{24}$ Of course, our focus on the averages reported in Tables 5 and 6 ignores the fact that the standard deviations are fairly substantial. But we believe that the size of the standard deviation is largely being driven by outliers associated with the maximum values listed in the table, which are themselves explained by our aggregation to the HS6 level. For example, in the US-German bilateral, the initial US offer made on 10/16/1950 for "Nail, barbers' and animal clippers, and blades: valued at more than $\$ 1.75$ per dozen," which falls into HS6 851020 , was to bind its tariff at a $10 \%$ ad valorem level, and this same tariff level was included in its final offer dated $3 / 21 / 1951$. But the US subsequently modified its final offer to Germany on 3/31/51, and in that modification it (a) maintained its offer of a $10 \%$ ad valorem tariff on "Nail, barbers' and animal clippers, and blades: valued at more than $\$ 1.75$ per dozen," but also added (b) an offer to bind its tariff on "Nail, barbers' and animal clippers: valued not over 50 cents per dozen" at the level of $1.75 \%$ ad valorem and (c) an offer to bind its tariff on "Nail, barbers' and animal clippers: valued over 50 cents but not over $\$ 1.75$ per dozen" at the level of $7.5 \%$ ad valorem, and both of these product categories also fall into HS6 851020. Hence, in this case our HS6 measure would indicate substantial intensive margin movement of the HS6 851020 tariff between the initial US offer and the (modified) final US tariff, when in fact at the 10 digit product level there is no intensive margin movement
} 
which describe the degree of adjustments to offers at the extensive margin over the course of the Torquay Round. ${ }^{25}$ After the initial offer and prior to a final agreement, the US modified its offers on roughly $12 \%$ of the HS6 products on which it made an initial offer, and US bargaining partners modified their offers to the US on approximately $14 \%$ of the HS6 products for which they made initial offers. Together these tables indicate that the most important dimension for negotiations was on the extensive margin, that is dropping and/or adding products from the negotiation, whereas there was minimal adjustment taking place on the intensive margin, that is, in the size of the tariff cuts being offered on any particular product. Moreover, $99.5 \%$ of the product-level offers that the US made over the course of the round are contained in its initial set of offers, indicating that at least for the US these extensive margin adjustments appear to be essentially a reallocation of a fixed set of offers across bargaining partners. ${ }^{26}$

Figure 6 demonstrates extensive margin movement in one detailed example, the US-Italy bilateral. Each colored line corresponds to one product. The x-axis represents time. As time goes on, the US modifies its offer by adding and removing products. Similarly, Italy's final offer to the US removes many products from its initial offer, while adding a handful. Revisiting the detailed example (the US bilaterals on lawn mowers) contained in Figure 4 similarly confirms the lack of intensive margin adjustment there, as embodied in the horizontal lines that connect each offer $(\mathrm{O})$ that ends in agreement $(\mathrm{A})$.

Stylized Fact 6: There is substantial two-way bargaining within narrow product categories, and only an extensive margin movement.

${ }^{25}$ As the second rows of the top and bottom panels of Table 3 indicate, after the initial request and prior to final agreement, the US modified its requests on approximately $19 \%$ of the HS6 products on which it made initial requests, and US bargaining partners modified their requests of the US on approximately $3 \%$ of the HS6 products for which they made initial requests. Recalling however our earlier observation in the context of Stylized Fact 2 that only one modification of requests occurred across the US bilaterals subsequent to the exchange of initial offers and the beginning of bilateral bargaining, it follows that subsequent to the exchange of initial offers virtually all of the extensive margin adjustments occur on the offer side, which is why we do not emphasize the extensive margin adjustment of requests in the text.

${ }^{26}$ The lack of intensive margin movement in the US bilaterals, both for the US and for its bargaining partners, is striking, and warrants further study. But we note here that it is suggestive of what one might expect if countries came to the bargaining table with their preferences revealed and their truthful offers put forward, along the lines of the dominant strategies we have described in section 2.2 in the presence of strict adherence to reciprocity and MFN. US preparations on the eve of the Torquay conference seem to support this view. As the secret memorandum in US State Department (1950) suggests, President Truman approved on September 26 the set of offers that US negotiators would apparently open with at Torquay on September 28: the memorandum to the President closes with "It is, of course, not possible to say that these offers if approved...will offer sufficient bargaining power to secure an agreement with all of the countries at Torquay. It may therefore be necessary to request additional authority on particular items as the negotiations proceed. However, it is believed that the offers which are recommended at this time will provide an adequate basis on which to begin the negotiations." 

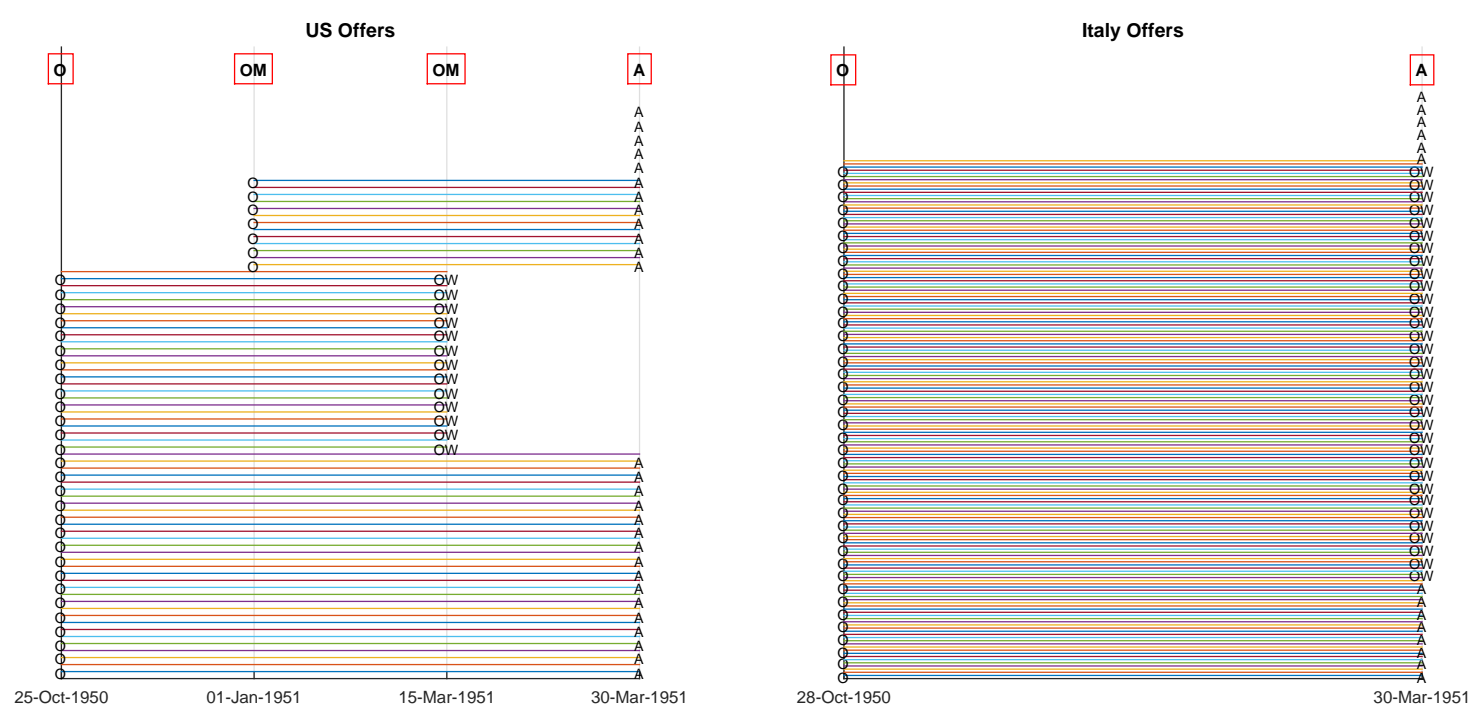

Figure 6: Extensive margin adjustments in US negotiations with Italy.

Notes: Each colored line corresponds to one product. The horizontal axis represents time. O indicates offer. A indicates agreement. $\mathrm{M}$ indicates modification. $\mathrm{W}$ indicates withdrawal.

and significant numbers of these two-way bargains occur within a single bilateral.

In Table 7, we present information on the degree of "two-way" exchanges of tariff cuts for similar products. The US was both fielding and seeking requests for tariff cuts on the same HS6 product category for 1,293 HS6 products, it made offers on 829 HS6 products for which it had also made a request, and it received offers on 972 HS6 products on which it had also made offers, with 444 of these two-way exchanges occurring within the same bilateral. Hence, for approximately half of the HS6 products on which the US received requests or made offers, it was simultaneously making requests of its trading partners and receiving offers on those products, and more than a third of these involved two-way exchanges within the same bilateral.

\subsection{Additional Stylized Facts: Trade Patterns and Bargaining}

We next develop a pair of additional stylized facts regarding the pattern of GATT tariff bargaining as it relates to trade patterns. To this end, we link the bargaining data at the HS6 level to US import values from 1948 compiled in the Census Bureau's United States Imports for Consumption of Merchandise report. This report provides import values by 7-digit Schedule A product category-country in 1948 current dollars into the US. We concord Schedule A codes to 
HS6 codes by text analysis and manual inspection to link to the bargaining data.

From these data, we calculate the Herfindahl-Hirschmann concentration index (HHI) of suppliers into the US and the fraction of supply from trading partners that were absent at Torquay. We further link these data to the Rauch (1999) indices of product differentiation, assigning a product to be undifferentiated if it is traded on an exchange or features a reference price. Finally, we link by HS4 code to the trade elasticities estimated in Broda et al. (2008) as a measure of product level market power. We use these additional variables in our data analysis of the next section, where we also discuss limitations associated with these variables.

The summary statistics for the trade and trade-related variables are in Table 8. The products on which the US made tariff-cut offers or received requests at Torquay are broadly similar on observable dimensions to the full set of products.

Stylized Fact 7: The largest suppliers of a product into a market are usually involved in the negotiations over the tariff on that product in that market.

In Table 9 we use the trade data together with the bargaining data to confirm an important and widely acknowledged feature of GATT tariff bargaining: the largest supplying interests are usually involved in the bargain. The top left-hand panel of Table 9 provides one way to gauge the importance of the largest suppliers in the negotiations. The first row reports the number and fraction of HS6 products offered by the US that did not include an offer to the top ranked Torquay supplier of that HS6 product into the US market, the second row reports the number and fraction of HS6 products offered by the US that did not include an offer to either the first or second ranked Torquay supplier of that HS6 product into the US market, and so on. As the numbers indicate, for roughly $79 \%$ of the HS6 products that the US offered at Torquay, at least one of the top 2 Torquay suppliers of that HS6 product into the US market received an offer on that product. The bottom left-hand panel displays the same measure based on "overall" (i.e., whether or not at Torquay) ranking of suppliers, and shows that, for roughly $68 \%$ of the HS6 products that the US offered at Torquay, at least one of the top 2 overall suppliers of that HS6 product into the US market received an offer on that product. The right-hand panels of Table 9 display the same measures, but for requests of the US made by its bargaining partners. The numbers in the right-hand panels show that the largest supplying interests were also important in generating requests, though not as important as in generating offers. ${ }^{27}$

\footnotetext{
${ }^{27}$ In principle the total numbers of HS6 products offered and requested in Table 9 should correspond to the numbers in the "Unique" column of Table 3, but in fact the totals underlying Table 9 are smaller. This is
} 
Stylized Fact 8: There can be a significant role in the negotiations for smaller suppliers of a product into a market where the largest suppliers are not involved.

We next use the trade and bargaining data to illustrate a less-appreciated point: despite the dominant role of the largest suppliers in negotiations, there can be a significant role for the smaller suppliers when the largest suppliers are not involved. This can be seen with the measures we present in Table 10 when those measures are compared with the measures in Table 9. The top left panel of Table 10 depicts the number and fraction of HS6 offers that the US made to the Nth ranked Torquay supplier of that HS6 product into the US market. ${ }^{28}$ For example, as can be seen from Table 10, roughly $40 \%$ of the US offers are made to suppliers ranked 3rd or lower, roughly $26 \%$ of the US offers are made to suppliers ranked 4th or lower, roughly $16 \%$ of the US offers are made to suppliers ranked 5 th or lower, and roughly $11 \%$ of the US offers are made to suppliers ranked 6th or lower. The question we wish to ask is, what is the role played by these lower-ranked suppliers when they receive an offer: Are they the biggest suppliers involved in the negotiations?; Or are they secondary players that receive an offer on the HS6 product that has also been made to a larger supplier? The answer is suggested by comparing the numbers in the top left panel of Table 10 to those in the top left panel of Table 9. Specifically, as the numbers in Table 9 show, roughly $21 \%$ of the HS6 products offered by the US are made when only the 3rd and lower-ranked Torquay suppliers are involved, and roughly $11 \%$ of the HS6 products offered by the US are made when only the 4th and lower-ranked suppliers are involved. This suggests that, when they are involved, the 3rd- and 4th- ranked Torquay suppliers sometimes play a primary role in the negotiations, in the sense that they are the largest suppliers receiving a US offer on the HS6 product under negotiation. Similar conclusions regarding overall supplier rank and requests follow from an examination of the other panels of Table 10 in comparison with those of Table $9 .{ }^{29}$

because calculating the rankings in Table 9 requires that HS6 imports into the US are strictly positive, and this is not always true in the 1948 import data, with such HS6 products then excluded from Table 9. The offer measures on the left-hand-side panels of Table 9 are probably overstated due to aggregation to the HS6 level. When the measures are recalculated on the subsample of data for which we have 7-digit schedule A codes, each of the fractions is roughly cut in half (the request measures on the right-hand side seem to be unaffected by aggregation). This, of course, only strengthens our claim. The column sums of the entries in Table 9 will be larger than the total numbers of HS6 products offered and requested that underlie the statistics presented in Table 9, because for example an HS6 product that is not offered to the first or second ranked supplier would be counted in both the first row and the second row of Table 9.

${ }^{28}$ The total numbers of HS6 offers and requests in Table 10 should in principle correspond to the numbers in the "Total" column of Table 3, but as with the corresponding comparison in Table 9, the totals in Table 10 are smaller, for the same reason as explained in note 27.

${ }^{29}$ The percentages we report in Tables 9 and 10 might overstate the role of smaller suppliers because these 


\section{Multilateral versus Bilateral Reciprocity}

As we noted in the Introduction, GATT reports from the early rounds emphasize that a key feature of GATT relative to previous attempts to negotiate MFN tariff reductions (e.g., the US Reciprocal Trade Agreements Act) is that the multilateral nature of GATT allowed countries to relax their need for strict bilateral reciprocity ("balance") in negotiations and focus instead on achieving reciprocity on a multilateral basis. As one early GATT report put it:

...The multilateral character of the Agreement enabled the negotiators to offer more extensive concessions than they might have been prepared to grant if the concessions were to be incorporated in separate bilateral agreements. Before the Geneva negotiations a country would have aimed at striking a balance between the concessions granted to another country and the direct concessions obtained from it without taking into account indirect benefits which might accrue from other prospective trade agreements; it might even have been unwilling to grant an important concession if it had been obliged to extend that concession to third countries without compensation. (ICITO, 1949, p. 10)

In effect, the claim is that GATT rounds allowed governments to exchange externalities across bilaterals in a balanced way that allowed them to maintain multilateral reciprocity.

Was the relaxation of strict bilateral reciprocity afforded by the multilateral nature of the GATT bargaining forum a key to GATT's success? One approach to assessing this claim would be to attempt direct measures of the degree to which the GATT bargaining outcomes violated bilateral reciprocity but conformed with multilateral reciprocity. A difficulty with this approach is that it requires knowledge of detailed trade elasticities that would apply to the countries

percentages are based on the 1948 US import data, and some countries (e.g. Germany) may appear to be small suppliers only because the 1948 data reflects World War II disruptions of normal trade patterns. To check for this possibility, we collected and concorded the 1938 US import data and recalculated the percentages in Tables 9 and 10 based on this prewar period. These percentages show an even greater role of smaller suppliers, suggesting that the impacts of World War II are not creating a false sense of the importance of smaller suppliers in the Torquay negotiations. A second possibility is that aggregation of the US import data to the HS6 level may disguise the importance of some suppliers at the tariff-line level. We have spot checked this second possibility by using the 7 digit Schedule A 1948 US import data, and have found that the apparent role of small suppliers is indeed reduced under these calculations. Nevertheless, even by these calculations the role of smaller suppliers remains more than just a curiosum, which is why in the text we emphasize this role. Further corroborating evidence on this point is provided in US State Department (1951b), where there are many documented examples of US concessions granted at Torquay to countries that were not principal suppliers at the time (and in some cases did not supply to the US market any of the product for which the US concession was granted; see for example, the discussion of US concessions granted to Austria on pp. 292-293). 
involved in the GATT negotiations during the period in which they were negotiating. ${ }^{30}$

Here we develop an alternative approach to assessing this claim. In particular, if countries were counting on indirect trade benefits from the MFN tariff cuts negotiated between third parties to achieve multilateral reciprocity in the Torquay Round, then we might expect to see reactions in the bilateral bargaining records of some countries when an unexpected event occurs in the bilateral negotiations of other countries (whereas according to the theory sketched out in section 2.2 no such reaction would be expected if strictly bilateral reciprocity had been demanded and achieved all along). Indeed, a report issued by the GATT Secretariat in the aftermath of the failure of the UK and its Commonwealth partners to reach agreement with the US in the Torquay Round suggests that such reactions to unexpected third-party events were thought to be an important feature of the round:

The fact that certain of the more important negotiations initiated between existing contracting parties did not result in agreements inevitably had some reactions on other negotiations. If, for example, the other countries engaged in tariff negotiations at Torquay had been sure that substantial concessions were going to be exchanged between the United Kingdom, Australia and New Zealand on the one hand, and the United States on the other, they might have been prepared, in the light of the benefits which they would have enjoyed from the automatic extension of these concessions to them, to go somewhat further in reducing their own tariffs. Substantial cuts in the tariffs of these Commonwealth countries, however, would inevitably have involved substantial reductions in some of the margins of preference which they accord to one another and the Commonwealth negotiators were not

\footnotetext{
${ }^{30}$ One could attempt to rely on simpler measures of reciprocity that abstract from elasticities and focus only on the average depth of tariff cuts or the trade volume covered by those cuts, but such measures seem to point in different directions and are difficult to interpret. For example, according to Table 5, the US agreed at Torquay to an average tariff cut of $32.5 \%$ and secured foreign tariff cuts from its bargaining partners that averaged $11.3 \%$, yet the foreign tariff cuts secured by the US applied to over 1 billion dollars of 1949 US exports while the tariff cuts to which the US agreed applied to less than half that amount of 1949 US imports (US State Department, 1951b, p. 1). In the next subsection we will make use of trade elasticities for the US under the assumption that the cross-product pattern of these elasticities applied to the period relevant to the Torquay Round, but this approach would have to be expanded to all trading countries of the time in order for us to use it to assess reciprocity directly, and elasticity estimates for many of the countries present at Torquay are not available. An additional difficulty with direct assessment of reciprocity is the prevalence of quotas during the Torquay period (often rationalized by dollar shortages and balance of payment exceptions). As Curzon (1966; pp. 70-1, pp. 85-6, Chapter VI) describes, quotas were regularly used in early round eras by many countries other than the US, which accounted in part for the willingness of countries to offer major tariff cuts in the first couple of rounds but which makes it difficult to draw a tight connection between tariff cuts and trade volume changes for these other countries. The concern is that tariff cuts were coincident with greater use of quotas, as a substitute instrument.
} 
prepared to agree to major tariff concessions of this kind at the price which the United States negotiators were prepared to offer in return. (ICITO, 1952, p. 9)

This discussion suggests an indirect way to evaluate the contribution to the success of GATT tariff bargaining of the relaxation of strict bilateral reciprocity. If the collapse of the bilateral bargains between the US on the one hand and the UK and a number of its Commonwealth partners on the other triggered significant changes in the remaining bilaterals that the US negotiated with third countries at Torquay, then this would be evidence that strict bilateral reciprocity was not a feature of the bargains that were anticipated to prevail on the eve of this collapse, and evidence therefore consistent with the view that the relaxation of strict bilateral reciprocity which was facilitated by the GATT multilateral bargaining forum was indeed important to the success of the GATT approach. ${ }^{31}$ On the other hand, if little or no change in the remaining US bilaterals is observed in response to this collapse, this would suggest that bilateral reciprocity between the US and each of its bargaining partners was in fact built in to the bargains all along, and that the relaxation of the need for strict bilateral reciprocity facilitated by the GATT multilateral forum was not a central reason for GATT's success.

We follow this logic with two tests. First, we check whether the US-UK breakdown led to a retrenchment of offers by US bilateral partners at the country level. Second, we test at the product level whether goods which were under negotiation with the UK prior to the breakdown were more likely to be re-offered by the US to other countries after the breakdown. ${ }^{32}$

To implement these tests, we must identify when the news of the US-UK/Commonwealth breakdown occurred. This news was officially announced at the GATT Secretariat on March 31, 1951, but The New York Times (1951a) broke the news with a dateline March 30 special

\footnotetext{
${ }^{31}$ To further relate this interpretation to our theoretical analysis in section 2.2 , we make two additional observations. First, if the failure of the US/UK bargain is regarded as random and exogenous, then under multilateral reciprocity any resulting changes in US proposals might be broadly interpreted as the utilization of an alternative dominant strategy for the US. Second, we note that the simple theory sketched out in section 2.2 does not explain why the relaxation of bilateral reciprocity in favor of multilateral reciprocity would matter to the success of tariff bargaining. Alternative models, however, may provide potential explanations. For example, as suggested in the Introduction, in a 3-good, 3-country model of triangular trade, where country $A$ exports good $a$ to country $B$, country $B$ exports good $b$ to country $C$, and country $C$ exports good $c$ to country $A$, negotiations over import tariffs can generate potential gains under multilateral reciprocity but not under bilateral reciprocity. More generally, empirical evidence of a beneficial role for multilateral reciprocity may motivate interesting and new theoretical analyses.

${ }^{32}$ It would be interesting to consider the impact of news about third-party bilaterals more generally on the pattern of offers at Torquay. But with our focus here on only the US bilaterals, we choose to restrict attention to the central surprise of the Round - the breakdown of the US-UK bilateral - and leave a more systematic investigation of these issues to future research that can consider the full set of Torquay bilaterals.
} 
press report, and it seems unlikely that even the March 30 announcement would have come as a complete surprise to the other negotiating countries at Torquay. Below we will report results that set the "news" date at February 18, because that was the day after the last action in the USUK bilateral - the UK's modification of its offer to the US on 2/17/1951 - and it seems plausible that general news of the disappointing UK response to the US request that it substantially reduce the margins of preference which it accorded to its Commonwealth partners would have become known to other negotiators soon after. But we also experiment with alternative news dates between March 1 and March 30.

We begin with the question: Did the willingness of US bargaining partners to make offers in their bilaterals with the US diminish once it was known that the US-UK/Commonwealth bilaterals had failed? Fixing 2/18/1951 as the date by which negotiators at Torquay had learned that the US-UK/Commonwealth bilaterals would fail, we calculate the total number of HS6 product-country pairs with an existing tariff offer to the US outstanding on 2/18/1951, summed across all US bilaterals except the US-UK, US-Australia and US-New Zealand bilaterals. ${ }^{33}$ This number is 2,333. We then calculate the total number of HS6 product-country pairs with a final tariff offer to the US at the end of the Round, again summed across all US bilaterals (with the failures of the US-UK, US-Australia and US-New Zealand bilaterals excluding these bilaterals automatically from this sum). This number is 2,396. Clearly, comparing these two numbers would not lead one to conclude that there had been a diminished willingness on the part of US bargaining partners to make offers in their bilaterals with the US after they had learned that the US-UK/Commonwealth bilaterals would end in failure. Performing this same calculation with the "news" date fixed at either 3/1/1951 or 3/30/1951 yields similar results.

However, on closer examination this simple difference is driven strongly by a suite of offers from France after the US-UK/Commonwealth breakdown. While these offers from France may have been influenced by the US-UK breakdown, the narrative from the time suggests that other factors unique to the France-US negotiation were probably more decisive. ${ }^{34}$ Eliminating France

\footnotetext{
${ }^{33}$ Of the other Commonwealth members at Torquay, only Canada had outstanding offers to the US on 2/18/1951, and the US-Canada bilateral concluded successfully.

${ }^{34}$ In particular, as Curzun (1966, p. 110) describes, France was alone in following a strategy at Torquay that relied heavily on threats of renegotiating the existing tariff concessions it had agreed to in prior GATT rounds (under the GATT renegotiation provisions contained in Article XXVIII that we described in section 2.2). Curzun notes that most countries renegotiated less than ten items, whereas France was the exception and "renegotiated some 200 items, only to find later, to quote one of her negotiators, "that it had neither been necessary nor worthwhile." This discussion raises the possibility that France abandoned this strategy late in the round, which may account for the large number of offers it made to the US subsequent to $2 / 17 / 1951$. That
} 
from the calculation produces a total number of outstanding offers to the US of 2,282 before and 1,856 after $2 / 18 / 1951$, a result that is consistent with the position that countries were counting on indirect trade benefits from the MFN tariff cuts negotiated between the US and its UK/Commonwealth bargaining partners to achieve (multilateral) reciprocity, and pulled back on their offers to the US in an attempt to reestablish reciprocity once they realized that these indirect benefits would not be forthcoming.

We next turn to the question: Did the failure of the US-UK/Commonwealth bilaterals lead the US to extend offers to countries directly on products where those countries had anticipated gaining access indirectly into the US market through the US-UK/Commonwealth bilateral? We estimate the following regression on the sample of HS6 codes for which the US made an offer:

$$
\begin{aligned}
& \text { USOffPost } t_{i, f}=\alpha_{H S 1}+\gamma_{f}+\beta_{1} U S O f f U K A U N Z_{i}+\beta_{2} \log \left(1+U S \text { Imp }_{i}\right)+ \\
& \beta_{3} \log \left(1+U S \operatorname{Imp}_{i, f}\right)+\beta_{4} \log \left(1+U S \operatorname{Imp} U K A U N Z_{i}\right)+\epsilon_{i f}
\end{aligned}
$$

where we include HS1 fixed effects, negotiating partner fixed effects, and condition on total US import volume, bilateral volume from each non-Commonwealth US negotiating partner, and volume from the Commonwealth countries. ${ }^{35}$ The key coefficient in equation (6.1) is $\beta_{1}$ which, if positive, indicates that a good was more likely to be offered after the US-UK/Commonwealth breakdown (i.e., USOffPost U $_{i, f}$ is more likely to take a value of 1 ) if it was part of the outstanding set of offers that the US had extended to the UK and its Commonwealth partners (i.e., when the dummy variable $U S O f f U K A U N Z_{i}$ takes a value of 1 ).

Table 11 provides the regression evidence (OLS and Probit), with the news date fixed at 2/18/1951. The coefficient on $U S O f f U K A U N Z$ is positive and significant in all specifications, as would be expected if the failure of the US-UK/Commonwealth bilaterals led the US to extend its offers to countries directly on products where those countries had anticipated that they would gain access indirectly into the US market through the US-UK/Commonwealth

possibility seems to be supported by news coverage at the time: a November 81950 article in The New York Times (1950b) ran with the headline "French Now Seek New Tariff Duties: Torquay Trade Body Amazed as Paris Negates Efforts to Relax Import Curbs"; while an article published by the Times (1951b) on March 11 1951 stated that "France, which was frightening all participants in November with the number of items on which she wanted to raise duties (mostly items on which the French granted reductions in the earlier meetings at Geneva and Annecy) has mollified most of her trading partners. The French have withdrawn some of their demands for revision and given quoted compensation in other cases in the form of reductions on some other items, all after prolonged and sometimes acrimonious bargaining in dozens of hotel rooms."

${ }^{35}$ Here and throughout we experimented with both HS1 and HS section fixed effects, finding that it made no material difference to our results, so we report results with HS1 fixed effects in both Tables 11 and 12 . 
bilaterals. Using news dates of 3/1/1951 and 3/15/1951 yields similar results, while if the official 3/30/1951 dateline of The New York Times press release is used for the news date, the results are still significant in the Probit, but overall the relationship is weaker. The results are robust to excluding offers to France.

Overall, these results provide indirect evidence that news of the breakdown in the USUK/Commonwealth bilaterals caused $3^{\text {rd }}$ countries to rebalance their bilaterals with the US, and hence evidence that bilateral reciprocity was not a feature of the bargains that were anticipated to prevail on the eve of this collapse, consistent with the view that the relaxation of bilateral reciprocity which was facilitated by the GATT multilateral bargaining forum was important for the success of the GATT approach. ${ }^{36}$ Our results also provide some specific support for the view expressed in the report by the GATT Secretariat quoted above, that this rebalancing took the form at least partially of a general retrenchment of offers to the US, but only if the US-France negotiations are treated as unique, as described above. If one treats the US-French negotiations as the same as others, our results suggest that this rebalancing still occurred, but that it was achieved not by an overall retrenchment of offers but rather by reorienting US offers directly to those $3^{\text {rd }}$ countries who stood to gain the most indirectly from successful US-UK/Commonwealth bargains.

\section{Bargaining under Reciprocity and MFN}

The theoretical analysis developed in section 2 highlights the potential value of recasting the GATT multilateral bargaining problem as a collection of simultaneous bilateral bargains that adhere strictly to the twin pillars of reciprocity and MFN. In particular, we have shown there that in the presence of these institutional features it is a dominant strategy for each country

\footnotetext{
${ }^{36}$ To be clear, our results reject the null hypothesis that the US Torquay bilaterals satisfied the restriction of bilateral reciprocity, because under this null the breakdown of the US-UK bilateral would not have triggered adjustments in the remaining US bilaterals. Moreover, the nature of the adjustments that we document are consistent with the kind of rebalancing that would be required to reestablish multilateral reciprocity after such a breakdown; and in further support of this interpretation we note that in US State Department (1951b, p. 6) the US provided a preliminary estimate (based on trade coverage) of "the indirect benefits, which will accrue to the United States as the result of concessions exchanged by other participants in the Torquay Conference in approximately 130 negotiations between pairs of countries," and concluded that these indirect benefits amounted to about 10 percent of the trade benefits accruing directly from its own negotiations at Torquay (a later accounting by the US International Chamber of Commerce, 1955 p. 24, put the number closer to 20 percent). Still, we can't rule out the possibility (i) that there was a general lack even of multilateral reciprocity before the US-UK breakdown, and (ii) that as a consequence there were externalities across bilateral bargains which were impacted by the US-UK breakdown and led to further adjustments in the remaining bilaterals.
} 
to truthfully reveal its (efficient-under-symmetry) politically optimal reaction curve tariffs on a product-by-product basis. An implication is that, by comparing initial offers to the final agreed tariff concessions in the round, we can construct measures of the success of the Torquay Round. ${ }^{37}$

Accordingly, we now assume that the US satisfied strict multilateral reciprocity and MFN in its Torquay tariff bargaining. ${ }^{38}$ Given this assumption, and defining the set $\mathcal{O}$ as the set of all HS6 products for which the US made an offer at Torquay, we can then use the union of the US initial offers in each of its Torquay bilaterals, denoted by $\tau_{i}^{U S}$ offer for product $i \in \mathcal{O}$, to identify the set of politically-optimal-reaction-curve tariffs for the US in the Torquay Round. Denoting the politically-optimal-reaction-curve tariffs for the US by $\tau_{i}^{U S} \mathrm{R}^{\mathrm{PO}}$, we therefore impose

$$
\tau_{i}^{U S \mathrm{R}^{\mathrm{PO}}}=\tau_{i}^{U S \text { Offer }} \forall i \in \mathcal{O}
$$

(Assumption 1)

We then characterize the degree of tariff bargaining failure at the product level for the US in the Torquay Round by a dummy variable TorqFail $_{i}^{U S}$ that takes the value 1 if the US did not reach agreement on product $i$ at Torquay and 0 if the US did reach an agreement on product $i$. Notice that our focus is on whether or not the US reached agreement at Torquay on product $i$ with at least one of its bargaining partners, and therefore whether a new US tariff commitment on product $i$ resulted from the Torquay Round; we leave as an important topic for future research the pattern of successful and failed offers across bargaining partners.

Implicit in our discussion of bargaining failure is the assumption that all US offers that should be made on efficiency grounds are in fact made, and therefore that for $i \notin \mathcal{O}$ US tariffs

\footnotetext{
${ }^{37}$ In principle, by imposing additional structure we could use this result to recover government preferences and construct the complete-information efficiency frontier for the round, against which the actual outcome of the round can be judged and the performance of counter-factual bargaining protocols can be assessed. For example, adopting the political economy model of Grossman and Helpman (1994), the assumption of strict adherence to reciprocity and MFN would allow us to utilize the initial offers from a given GATT round to estimate the value that each government places on lobby contributions along the lines of Goldberg and Maggi (1999), and with these estimates we could then construct the efficiency frontier for the round. This would require data from all of the bilaterals of a given round, however, and so we leave this more ambitious program for future research.

${ }^{38}$ Entering into the Torquay negotiations the US did maintain a small number of tariff preferences (e.g., on sugar imports from Cuba), but by the conclusion of the Torquay Round the US had terminated even these tariff preferences and maintained only MFN tariffs (see United Nations, 1952, p. 204). As a consequence, the only strong assumption we are making here is that the US satisfied strict multilateral reciprocity. We emphasize, too, that we are only assuming that the $U S$ satisfied strict multilateral reciprocity and MFN in its Torquay tariff bargaining, not that its bargaining partners also did. Hence, as we will exploit below, there could still exist bargaining frictions generated on the side of US bargaining partners (e.g., one-sided private information or one-sided bargaining externalities) that could give rise to strategic behavior on the part of US bargaining partners and account for bargaining failure in US bilaterals.
} 
are already at their politically optimal levels. Below we will relax this assumption and allow that bargaining failure may also take the form of US offers that are not made. As a separate matter, we could characterize the degree of bargaining failure with a continuous variable that measures the distance between the initial US offer and the final agreed US tariff. But as we have established in section 5, conditional on an agreement occurring there is almost no movement on the intensive margin between the initial offer and the final agreed tariff, so our dichotomous bargaining failure variable TorqFail ${ }^{U S}$ captures the relevant variation in the data.

Our goal is now to understand the patterns of US bargaining failure as displayed by TorqFail ${ }^{U S}$ with factors that could introduce bargaining frictions - and thereby potentially account for this failure - but would not invalidate Assumption 1. To this end, we consider the following seven factors:

(i) Bargaining Externalities: As a partial check on our assumption that the US satisfied strict multilateral reciprocity and MFN in its Torquay tariff bargaining, we include a measure of foreign exporter concentration on the right-hand side of the failure equation, and check to see whether there is evidence that the US faced a free-rider problem. If, as we assume, the US abides by MFN and its bargains satisfy strict multilateral reciprocity, then bargaining externalities should not lead to a free-rider problem for the US. ${ }^{39}$ But under MFN, if multilateral reciprocity is not achieved, $3^{\text {rd }}$-party externalities could lead to free rider problems, the more so the less concentrated are the foreign supplier-countries into the US market. ${ }^{40}$ To perform this check, we use the US bilateral import data from 1948 as described in the previous section to create the following variable: for each US product $i$ we construct the Herfindahl-Hirschmann concentration index among all Torquay-country suppliers of that product into the US market. We denote this variable by $H H I$. If the US faces a significant free-rider problem among the supplier-countries at Torquay (we consider supplier-countries not at Torquay below), HHI should be negatively

\footnotetext{
${ }^{39}$ Of course, free-rider issues might still arise if the export supply adjustments embedded in the definition of reciprocity are realized gradually over time, as problematic $3^{\text {rd }}$-party externalities might then be experienced in the short run. Our simple model abstracts from these considerations as a first pass.

${ }^{40}$ See Ludema and Mayda (2013) for related ideas regarding the impact of supplier-country concentration on the free rider problem. Ludema and Mayda develop a model predicting that exporter participation in negotiations on a given MFN tariff reduction is limited by the potential for free riding and where the negotiated tariff level is efficient for the participants in the negotiation on that good, leading them to interact measures of exporter concentration with measures of importer market power as a predictor of the negotiated tariff level in their empirical specification. In order to exploit the GATT bargaining data, we pursue a related but distinct approach, focusing directly on the impact of supplier concentration on the tariff offers made and their probability of success. As we describe further below, we also include measures of importer market power.
} 
related to our measure of US bargaining failure: the higher our measure of exporter-country concentration into the US market, the smaller the free-rider problem and the lower the chance of US bargaining failure. Finding this negative relationship would be evidence against our Assumption 1. On the other hand, in the absence of a significant free-rider problem among the supplier-countries at Torquay, concentration of supply of product $i$ could actually raise the probability of offer failure, if such concentration simply constrains the number of countries to which the US can make an offer on product $i$ without appreciably decreasing the probably that any single offer would fail. We therefore interpret a positive (or zero) relationship between supplier-country concentration and US offer failure as evidence consistent with Assumption 1.

It might be thought that the relationship between bargaining success and the concentration of export suppliers is hard-wired into GATT negotiations by the principal supplier rule. Recall, though, that the definition of principal supplier contained in the original 1947 GATT bargaining protocol and quoted above in section 3 explicitly provides for the possibility of defining principal supplier status based on the cumulative trade share of countries present at Torquay even if no single country alone has a principal supplying interest, suggesting that it was anticipated that concentration of the suppliers present at a round need not be the critical factor in bargaining success of failure. Our theoretical results point to reciprocity as a potential force for overcoming the free-rider issue even when the concentration of suppliers is not high.

(ii) UK Preferential Trade Agreements: US bargaining failures could be associated with the existence of tariff preferences in the UK. This reflects the well-known possibility of a "stumbling block" relationship between PTAs and multilateral liberalization, but the particular mechanism here is novel: for the UK and its Commonwealth partners, such preferences would violate MFN and lead thereby to the possibility of strategic behavior in the US/UK and US/UK-Commonwealth bilateral bargains; and this possibility of strategic behavior in turn potentially could result in bargaining failures for the US in products where the UK or UKCommonwealth countries are a principal supplier into the US market. As long as the US does not itself have preferences and hence abides by MFN (and expects multilateral reciprocity), Assumption 1 still holds; thus, the US would continue to have a dominant strategy in which it offers its politically-optimal-reaction-curve tariffs. The UK and its Commonwealth partners, however, might have additional strategic considerations when making their tariff offers, since their tariffs may generate $3^{r d}$-party externalities due to the PTAs in which they participate. As 
a consequence, their tariff offers may differ from their politically-optimal-reaction-curve tariffs. In this way, such PTAs may act as stumbling blocks to GATT/WTO multilateral liberalization because they introduce strategic considerations into the GATT bargaining setting that are not present for countries that abide by MFN. ${ }^{41}$ Making use of the US bilateral import data from 1948, we check for this possibility by asking if a dummy variable - whose $i^{\text {th }}$ value is 1 when the UK and UK-Commonwealth countries together are the principal suppliers into the US market of product $i$ and 0 otherwise - is positively related to our measure of US bargaining failure. We denote this dummy variable by $P T A .^{42}$

(iii) Barter: US bargaining failures could be associated with the lack of a double coincidence of wants that barter requires, again a possibility that would not invalidate Assumption 1. To check for this, we make use of the bargaining and 1948 US import data to construct a variable whose $i^{\text {th }}$ value is the ratio of the number of HS6 product requests that the US makes of the largest volume exporter to which the US made an offer on product $i$, relative to the number of such HS6 product offers that the US made to that country. We denote this variable by $W A N T$. For a product $i$ where this measure is low, the double coincidence of wants needed for the US to successfully complete a bargain over its tariff on product $i$ is likely to be lacking, and bargaining failure could result for that reason. Hence, we expect that $W A N T$ should be negatively related to our measure of US bargaining failure.

(iv) Preserving Bargaining Power for Future Rounds: It is possible that US bargaining failures could be associated with the degree to which countries absent from the Torquay Round constitute principal suppliers of product $i$, measured by the share of 1948 US imports of product $i$ that are supplied by countries not present at the Torquay Round. We denote this variable by $A B S E N T$. The absence of principal suppliers from Torquay would not invalidate

\footnotetext{
${ }^{41}$ The Benelux countries were also members of a PTA. But unlike the UK Commonwealth, theirs was a customs union, and following arguments similar to those in Bagwell and Staiger (1999, 2001) it can be shown that customs unions do not invalidate our dominant strategy arguments made in section 2 and therefore should not be the source of any particular bargaining frictions.

${ }^{42}$ Notice that our investigation of possible stumbling-block effects of PTAs adopts a different focus from that typical in the literature (e.g., Limao, 2008, and Estevadeordal, Freund and Ornelas, 2008). In the context of the Torquay Round, the typical focus would examine whether the UK was less likely to cut its MFN tariffs on products where its Commonwealth partners enjoyed preferential access to its markets, and similarly for each UKCommonwealth partner. We focus on whether non-Commonwealth trading partners (in particular the US) are less likely to succeed in cutting their MFN tariffs in a reciprocal bargain when the UK or a UK-Commonwealth country is the principal supplier of the product into the US market.
} 
Assumption 1; and whether or not it would lead to bargaining failure as we have defined it would depend in part on whether the US could make use of the so-called "split-concessions" bargaining technique that Beckett (1941) claims was utilized by the US in the context of the US Reciprocal Trade Agreements Act. If the absence of principal suppliers from Torquay does result in bargaining failure, then we would expect to find that $A B S E N T$ is positively related to our measure of US bargaining failure.

(v) Previously Bound Tariffs The Torquay Round was the third GATT bargaining round, and by the beginning of this round the US had in place a set of tariff commitments to which it had agreed over the first two rounds. ${ }^{43}$ It is possible that the presence of previously bound tariffs could help predict the likelihood of bargaining failure at Torquay in several ways. One possibility is simply that a previous tariff binding indicates that the inefficiency in the level of that tariff has been largely addressed in previous rounds, and there is little left to bargain over for that tariff. Under this possibility, we would expect that the presence of previously bound US tariffs would increase the chance of bargaining failure. But "gradualism," whereby the reductions on a single tariff are purposefully spread over many rounds, is a widelyacknowledged feature of GATT tariff liberalization. And from this perspective the presence of previously bound US tariffs might be expected to predict a reduced chance of bargaining failure at Torquay, because the early success suggests that the ingredients for success in further negotiated reductions in that tariff are also likely in place. ${ }^{44}$ To allow for these possibilities, we create the variable $P R E V B N D$, which is defined as a dummy variable whose $i^{t h}$ value is 1 if the US has a pre-existing GATT tariff commitment on product $i$ at the beginning of the Torquay Round and 0 otherwise. If the gradualism effect dominates, then we would expect to

\footnotetext{
${ }^{43}$ As Hoda (2001, pp. 84-85) describes and as we have noted above, the tariff bindings negotiated in the first (Geneva 1947) round came up for renewal during the Torquay Round and could have been the subject of Article XXVIII renegotiations under a parallel process at Torquay. In principle these renegotiations might be important for understanding the broader tariff negotiations at Torquay, but the derestricted GATT bargaining data does not yet include records on any of the renegotiations that occurred. However, as Hoda notes, the US stated that it did not wish to invoke Article XXVIII during the Torquay negotiations, and it carried out discussions for "certain adjustments" under Article XXVIII on just 3 product-level tariffs. Given our focus on the US bilaterals at Torquay, it therefore seems unlikely that the lack of Article XXVIII bargaining records would substantially undercut our ability to understand the bargaining behavior of the US in the Torquay Round.

${ }^{44}$ Whether or not evidence of gradualism would be consistent with our Assumption 1 would depend on the reasons for gradualism. Gradual tariff reductions that reflect split concessions and the gradual accession of countries through time would not pose a problem for Assumption 1, but gradualism that reflects the evolution of binding self-enforcement constraints (see for example Staiger, 1995, Devereux, 1997 and Bond and Park, 2002) could invalidate Assumption 1.
} 
find that $P R E V B N D$ is negatively related to our measure of US bargaining failure.

(vi) Differentiated Goods: Ossa (2014) has argued that the existence of differentiated goods can interfere with the ability of MFN and reciprocity to neutralize $3^{\text {rd }}$-party externalities. This suggests that US bargaining failures (stemming from bargaining externalities) could be associated with the presence of differentiated goods imported into the US, even if the US abides by MFN and achieves strict multilateral reciprocity in its Torquay bargains. Of course, in the presence of product differentiation, the scope of application of the MFN principle becomes critical: At what point do differentiated products cease to become "like products," and thereby not require a common tariff treatment under the MFN principle? The answer to this question is important in the present context, because as Ossa demonstrates the magnitude of the $3^{\text {rd }}$-party externality is directly proportional to the degree of product differentiation over which the MFN principle applies (inversely proportional to the elasticity of substitution across the products), and so the externality should be small to the extent that like products are narrowly defined for purposes of the MFN principle. ${ }^{45}$ Nevertheless, to allow for this possibility we use the Rauch (1999) index concorded to each 1948 US import product $i$, and denote a product as undifferentiated if the Rauch index lists the product as being traded on an exchange or having a reference price. ${ }^{46}$ We denote this variable by UNDIFF. Based on Ossa's findings, we would expect to find that $U N D I F F$ is negatively related to our measure of US bargaining failure.

(vii) Market Power The terms-of-trade theory predicts that the goods for which negotiated reductions in tariffs are the most attractive are those for which the conceding country holds more market power. This suggests that a given level of bargaining frictions would be less likely to lead to US bargaining failure over product $i$ the greater the US market power in product $i$, and hence the greater the potential surplus from agreement. We therefore condition on market power using the log inverse foreign export supply elasticity $\left(\log \left(\omega_{i}\right)\right)$ as estimated by Broda, Limao, and Weinstein (2008) for the US at the HS4 level, and we expect to find that $\log \left(\omega_{i}\right)$ is negatively related to our measure of US bargaining failure. We apply the HS4

\footnotetext{
${ }^{45}$ As illustrated for example in note 24 , the product lines on which individual tariffs are defined and within which MFN would apply can be and often are quite detailed and narrowly defined.

${ }^{46}$ We treat products which do not have a Rauch index as differentiated. Dropping these observations does not meaningfully change the results we present, however we lose a substantial number of observations in that case. Needless to say, applying the Rauch index to data from 1948 requires a large leap of faith. We discuss this further in note 48 below.
} 
level estimate to all HS6 codes within the HS4 description, and emphasize that this measure is estimated with trade data covering the 1990's and early 2000's which is much later than our period of interest. ${ }^{47}$ Thus we are making the strong assumption that the relative magnitudes of these elasticities across goods has not changed over the relevant time period. ${ }^{48}$

Finally, as noted above we have thus far imbedded into our discussion of bargaining failure the assumption that all US offers that should be made on efficiency grounds at Torquay were in fact made, and therefore that US tariffs are already at their politically optimal levels for $i \notin \mathcal{O}$. But it is reasonable to expect that the US might have targeted certain kinds of offers at Torquay and left others for future rounds: for example, it was well known at the time that a major goal of the US at Torquay was to use its tariff offers to bargain down the external MFN tariffs of Commonwealth countries and thereby achieve a reduction in the margin of tariff preferences that they offered to each other. And it also seems reasonable to expect that the US may have refrained from making tariff offers even when its tariffs were set above their politically optimal levels if it thought that those offers would fail with high probability. Defining $\mathcal{M}$ as the set of

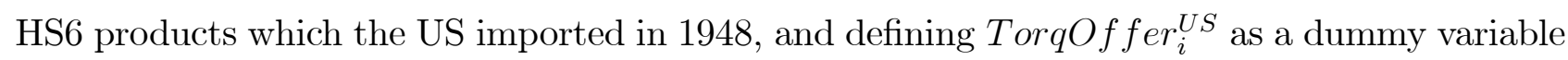
whose $i^{t h}$ value is 1 if the US made an offer at Torquay on product $i \in \mathcal{M}$ and 0 otherwise, we therefore estimate an "offer equation" in addition to our "failure equation," to allow that bargaining failure may also take the form of offers that are not made. ${ }^{49}$

Collecting these points, we estimate the following regressions:

$$
\begin{aligned}
\operatorname{TorqOffer}_{i}^{U S}= & \beta_{H S 1}+\beta_{1} H H I_{i}+\beta_{2} H H I_{i}^{2}+\beta_{3} P_{T} A_{i}+\beta_{4} W A N T_{i} \\
& +\beta_{5} A B S E N T_{i}+\beta_{6} U N D I F F_{i}+\beta_{7} \log \left(\omega_{i}\right)+\beta_{8} R E Q_{i}+\beta_{9} P R E V B N D_{i}+\epsilon_{i}
\end{aligned}
$$

$$
\begin{aligned}
\operatorname{TorqFail}_{i}^{U S}= & \alpha_{H S 1}+\alpha_{1} H H I_{i}+\alpha_{2} H H I_{i}^{2}+\alpha_{3} P T A_{i}+\alpha_{4} W A N T_{i} \\
& +\alpha_{5} A B S E N T_{i}+\alpha_{6} U N D I F F_{i}+\alpha_{7} \log \left(\omega_{i}\right)+\alpha_{8} R E Q_{i}+\alpha_{9} P R E V B N D_{i}+\epsilon_{i}
\end{aligned}
$$

\footnotetext{
${ }^{47}$ As a robustness check, we also experimented with the 4-digit and 6-digit export supply elasticity estimates contained in Nicita, Olarreaga and Silva (2014) and provided to us by Marcelo Olarreaga, and found similar results to those we report below.

${ }^{48}$ If this mis-measurement and the analogous mis-measurement associated with our use of the Rauch (1999) index for the 1948 import data is random across products, we would expect it to attenuate the results we find. A more subtle form of mis-measurement could arise whereby the US granted concessions on products that were on their way to having centralized exchanges, or whose market power was trending upward. Future research could use the data we are collecting across GATT rounds to re-estimate elasticities from this time period.

${ }^{49}$ We also check whether accounting for selection into offers affects the failure equation.
} 
where equation (7.1) is a Probit for whether the US makes an offer on product $i \in \mathcal{M}$, and where equation (7.2) is a linear probability model of whether product $i \in \mathcal{O}$, on which the US made an offer at some point during Torquay, ultimately resulted in a final concession. The variable $R E Q_{i}$ is a dummy variable for whether the US received a request from a counterparty at Torquay to reduce its tariff on product $i$, and $\beta_{H S 1}$ and $\alpha_{H S 1}$ are HS1 fixed effects. ${ }^{50}$ The $W A N T_{i}$ variable in the offer equation is constructed slightly differently from the $W A N T_{i}$ variable in the failure equation as we described that variable above. Specifically, for the offer equation $W A N T_{i}$ is constructed as a variable whose $i^{\text {th }}$ value is the ratio of the number of HS6 product requests that the US makes of the largest volume exporter from which the US received a request on product $i$, relative to the number of such HS6 product requests that the US received from that country. Finally, we include both $H H I_{i}$ and $H H I_{i}^{2}$ in each equation to allow for the possibility that free-rider effects might vary non-linearly with exporter-country concentration.

The results from estimating equation (7.1) and (7.2) are contained in Table 12. The first four columns present the results of estimation with $\log \left(\omega_{i}\right)$ omitted, and the last four columns present the estimation with $\log \left(\omega_{i}\right)$ included (and a roughly $10 \%$ reduction in the sample size due to the exclusion of products for which $\log \left(\omega_{i}\right)$ is unavailable). In both sets of specifications, we also check robustness with respect to different assumptions on accounting for selection into offers in the failure equation. The second and fifth columns do not include any selection correction. The third and sixth columns include the inverse Mills ratio from the offer equation, but do not exclude any other variables in the failure equation. The fourth and eighth exclude REQ and HS1 fixed effects from the failure equation. Across these specifications, we do not find evidence that selection into offers significantly affects the results of the failure equation; nonetheless, we focus on the results where we account for selection, and exclude REQ and HS1 fixed effects from the failure equation. ${ }^{51}$ Most of the coefficients of interest are significant and

\footnotetext{
${ }^{50}$ We also include $\hat{\lambda}_{i}$, the estimated inverse Mills ratio from the Probit to correct for non-random selection of products into offers, as the failure regression is conditional on there being an initial offer. However, we find that this correction does not affect our results.

${ }^{51}$ The inclusion of REQ and HS1 in the offer equation are based on the following observations: (i) for any tariff that the US government wished to offer up for negotiations at Torquay, it had to secure tariff-cutting authority from Congress by the October 1 date at which the offer stage of the Torquay Round bargaining was set to commence, (ii) there are political costs to securing tariff-cutting authority, (iii) these political costs are higher for tariffs that have not been requested by any trading partner, because US exporters cannot then be pitted against US import-competing interests to mitigate the costs, and (iv) these political costs vary by industry. The exclusion of these variables from the failure equation then follows based on the view that, once authority to make tariff-cutting offers has been granted, these particular costs have been borne and so they do not impact the probability of offer failure. That we find no evidence of selection into offers could of course be an indication that our offer equation is poorly specified. But it could also indicate that US offers were largely determined
} 
of the expected sign. A couple of specific points are noteworthy.

First, focusing on the failure equation (columns 4 and 8 of Table 12), there is strong evidence of a positive relationship between bargaining failure and the concentration of Torquay-country suppliers into the US market, the opposite of what would be expected if the free-rider problem were present. This relationship appears to be non-linear, and it turns slightly negative for very high levels of concentration (when there exists a single supplying country whose share among Torquay suppliers into the US market exceeds 90\%). But the central message of the failure equation estimates regarding bargaining externalities and the free-rider problem is that there is little if any evidence for the negative relationship between $H H I$ and our measure of US bargaining failure that would be expected if the free-rider problem is present. In fact, according to our estimates, an increase in the HHI of a product's supply into the US from one standard deviation below the mean HHI to one standard deviation above the mean would increase the probability of bargaining failure by 0.09. Turning to the offer equation (columns 1 and 5 of Table 12), the estimates imply that for low levels of supplier concentration a rise in the concentration of Torquay country suppliers increases the likelihood of an offer, possibly indicating the presence of a free-rider problem at low levels of Torquay supplier concentration; but for concentration levels beyond a mid-level threshold, higher concentration reduces the chances of an offer, again the opposite of what would be expected if the free-rider problem were present. And here according to our estimates, an increase in the HHI of a product's supply into the US from one standard deviation below the mean H H I to one standard deviation above the mean would decrease the probability of a US offer by 0.11 .

We interpret these coefficient estimates as together providing substantial support for the position that the free-rider problem among those countries present at Torquay was likely not a major issue for the US in its Torquay negotiations. This interpretation is in turn consistent with our Assumption 1 and broadly supports the view that the US abided by MFN and strict multilateral reciprocity in the Torquay Round. That said, our coefficient estimates do point to the existence of a free-rider issue for offers at low levels of concentration, suggesting that an important task of future research is to confront the complications associated with $3^{\text {rd }}$-party externalities that arise when adherence to reciprocity and/or MFN is not strict.

A second noteworthy finding from Table 12 concerns the impact of PTAs. As would be by US tariff-cutting authority, and that offer-failure probabilities were very difficult for the US government to predict at the time that it was seeking this tariff-cutting authority. 
expected based on the bargaining-friction stumbling block arguments described above, columns 4 and 8 of Table 12 imply that US bargaining failure is more likely for products that are principally supplied to the US market by the UK and its Commonwealth partners (though this effect loses significance when $\log \left(\omega_{i}\right)$ is included). On the other hand, the offer equations in columns 1 and 5 indicate that PTAs stimulate offers, a finding that is consistent with the emphasis placed by the US on reducing the size of within-Commonwealth tariff preferences by bargaining down their external MFN tariffs at Torquay. ${ }^{52}$ Hence, our estimates indicate that PTAs can have two counter-acting effects: they can stimulate offers, and in this way can be seen as "building blocks" of negotiated MFN tariff reductions, but they also make those offers more likely to fail and in this way are stumbling blocks to the multilateral system. The overall effect of PTAs in the Torquay Round - that is the impact on generating successful offers and hence final agreed tariff concessions - can be gauged by evaluating the net effect of these two forces for each observation in our sample and taking the mean of the net effects. When we do this using the estimates in columns 1 and 4 of Table 12, we find that the probability of a final agreed US tariff concession in the Torquay Round rises from roughly 0.36 when PTAs are absent to 0.41 in the presence of PTAs, which amounts to a sizable building block effect. ${ }^{53}$

Finally, Table 12 also indicates a strong positive relationship between US market power and the likelihood and likely success of US offers at Torquay (consistent with the terms-of-trade theory), a strong positive relationship between previous US tariff bindings and the likelihood and likely success of US offers at Torquay (consistent with a gradualism story), a strong positive impact on the likelihood of offers when the double coincidence of wants needed for barter to occur is present, and a strong positive relationship between the degree of product differentiation and the likelihood of bargaining failure. This last result is in line with Ossa's (2014) prediction, and provides further support for the view that allowing for $3^{\text {rd }}$-party externalities

\footnotetext{
${ }^{52}$ This finding is also consistent with a view often expressed by trade policy practitioners at the time of the early GATT rounds, that multilateral GATT negotiations were a needed response to the formation of PTAs. For example, in remarks made before the Joint Economic Committee, former Secretary of State Christian Herter appealed to the formation of the European Community (EC) in 1957, and the phase-in of the EC customs union among the original six EC countries over the next decade and the prospect of an integrated EC market that this implied, as a key reason that the US should push for a new GATT round of multilateral tariff negotiations (see Herter, 1961). The US efforts in this regard led eventually to the initiation of the Kennedy Round of GATT negotiations in 1964. That said, our finding that PTAs stimulate offers is reversed when we re-estimate the regressions in Table 12 using the 1938 US import data (see also note 29), and so we view the results in Table 12 as suggestive of a possible building block effect but not conclusive.

${ }^{53}$ When we redo this calculation weighting each observation in our sample by US import volumes, the corresponding numbers are 0.37 when PTAs are absent and 0.41 when PTAs are present.
} 
in the analysis of GATT tariff bargaining is an important task for future research. ${ }^{54}$

\section{Conclusion}

Our initial look at the Torquay Round bargaining records has shown that GATT multilateral tariff bargaining displays an array of interesting features. We document that governments bargain with back-and-forth offers on the particular tariffs they are willing to cut, but they make take-or-leave offers on the depth of these cuts. They make counter-proposals by adjusting the set of tariff cuts they are willing to offer in light of the cuts offered by their bargaining partners, but they do not propose adjustments to what their bargaining partners have offered. The big supplying countries play the dominant role in negotiations, but the role of smaller supplying countries can also be significant. Initial offers sometimes sit dormant on the table for long periods of time and are then finalized with a single modification at the time that other bargains are concluded.

We also show that tariff cuts are more likely to be offered on products where the country has substantial market power, and that these offers are more likely to succeed. We find evidence that tariff cuts are more likely to be offered by a country when members of a PTA from which that country is excluded have a principal supplying interest; and while these offers are individually less likely to succeed, on net PTAs generate greater numbers of successful offers and hence appear to be building blocks rather than stumbling blocks for MFN tariff liberalization. We find little evidence of a major free-rider problem associated with the bilateral-bargainingunder-MFN approach that GATT has frequently adopted in its rounds of multilateral tariff bargaining. And we use the breakdown of the US-UK bilateral midway through the Torquay Round as a natural experiment to provide novel evidence that GATT's ability to facilitate multilateral reciprocity indeed aided liberalization.

Many of these features seem consistent with the predictions of the terms-of-trade theory of trade agreements, as we have detailed above. In our analysis we have built on the implications of this theory augmented by the institutional features of reciprocity and MFN, but we have left the full exploitation of these implications for future work. And some of the features seem to reflect a more general bargaining environment, pointing to the importance of more general theoretical structures and additional theoretical work to guide the analysis and interpret the

\footnotetext{
${ }^{54}$ Our evidence on gradualism may also point to the importance of this task for future research, especially if the reasons for gradualism relate to self-enforcement constraints (see also note 44).
} 
results, theoretical work that is needed in any event if the focus of analysis is to expand beyond the US Torquay bilaterals to include the bilaterals of countries such as the UK and its Commonwealth partners that were clearly not abiding by MFN at the time of the early GATT rounds. All of these features would be unknowable without the detailed bargaining data that the WTO has begun to make publicly available. In this light, as more and more of this data becomes accessible to researchers, we view our initial look at the GATT bargaining data as providing a promising view for the road ahead.

\section{References}

Admati, Anat R. and Motty Perry (1987), "Strategic Delay in Bargaining," Review of Economic Studies, LIV, 345-364

Bagwell, Kyle and Robert W. Staiger (1999), "An Economic Theory of GATT," American Economic Review 89(1): 215-48

Bagwell, Kyle and Robert W. Staiger (2001), "Reciprocity, Non-discrimination and Preferential Agreements in the Multilateral Trading System," European Journal of Political Economy, June

Bagwell, Kyle and Robert W. Staiger (2002), The Economics of the World Trading System, Cambridge, MA: The MIT Press

Bagwell, Kyle and Robert W. Staiger (2005), "Multilateral Trade Negotiations, Bilateral Opportunism and the Rules of GATT/WTO," Journal of International Economics 67(2): 268-94

Bagwell, Kyle and Robert W. Staiger (2010a), "The WTO: Theory and Practice," Annual Review of Economics, 2: 223-56

Bagwell, Kyle and Robert W. Staiger (2010b), "Backward Stealing and Forward Manipulation in the WTO," Journal of International Economics, 82(1): 49-62

Bagwell, Kyle and Robert W. Staiger (2011), "What do trade negotiators negotiate about? Empirical evidence from the World Trade Organization," American Economic Review 101(4): 1238-73

Bagwell, Kyle and Robert W. Staiger (forthcoming), "The Design of Trade Agreements," in Kyle Bagwell and Robert W. Staiger (eds) Handbook of Commercial Policy. Elsevier, Amsterdam. 
Beckett G (1941), The Reciprocal Trade Agreements Program. New York: Columbia Univ. Press

Bond E, Park J-H (2002), "Gradualism in trade agreements with asymmetric countries," Review of Economic Studies 69: 379-406

Bown, Chad P. and Meredith A. Crowley (2013), "Self-Enforcing Trade Agreements: Evidence from Time-Varying Trade Policy," American Economic Review 103(2): 1071-1090

Broda, Christian, Nuno Limao, and David E. Weinstein (2008), "Optimal Tariffs and Market Power: The Evidence," American Economic Review, 98(5): 2032-65

Cramton, Peter (1992), "Strategic Delay in Bargaining with Two-Sided Uncertainty," Review of Economic Studies, 59(1): 205-225

Crawford, Gregory S., and Ali Yurukoglu (2012), "The Welfare Effects of Bundling in Multichannel Television Markets," American Economic Review, 102(2): 643-85

Curzon, Gerard (1966), Multilateral Commercial Diplomacy: The General Agreement on Tariffs and Trade and its Impact on National Commercial Policies and Techniques, Praeger: New York

Devereux, M.B. (1997), "Growth, Specialization, and Trade Liberalization," International Economic Review, 38(3)

Estevadordal, Antoni, Caroline Freund, Emanuel Ornelas (2008), "Does regionalism affect trade liberalization toward nonmembers?," Quarterly Journal of Economics 123(4): 1531-75

Feketekuty, Geza (2008), "A Guide to Services Negotiations," in Aadita Mattoo, Robert M. Stern and Giani Zanini (eds) A Handbook of International Trade in Services, The World Bank, Oxford University Press, pp. 542-592

Goldberg, Pinelopi and Giovanni Maggi (1999), "Protection for Sale: An Empirical Investigation," American Economic Review, 89(5): 1135-55

Gowa, Joanne and Soo Yeon Kim (2005), "An Exclusive Country Club: The Effects of the GATT on Trade, 1950-94," World Politics, 57(4): 453-478

Grossman, Gene M. and Elhanan Helpman (1994), "Protection for Sale," American Economic Review 84(4): 833-50 
Herter, C. (1961), Statement before the Joint Economic Committee of the Congress of the United States, December 4-14, pp. 8-13

Hoda, Anwarul (2001), Tariff Negotiations and Renegotiations under the GATT and the WTO: Procedures and Practices, WTO and Cambridge University Press

Irwin, Douglas A. (1995), "The GATT in Historical Perspective," American Economic Review Papers and Proceedings 85 May: 323-328

Interim Commission for the ITO (1949), The Attack on Trade Barriers: A Progress Report on the Operation of the General Agreement on Tariffs and Trade. Geneva, August

Interim Commission for the ITO (1952), GATT in Action: Third Report on the Operation of the General Agreement on Tariffs and Trade. Geneva, January

Karacaovali Baybars and Nuno Limao (2008), "The Clash of Liberalizations: Preferential vs. Multilateral Trade Liberalization in the European Union," Journal of International Economics 74(2): 299-327

Keniston, Daniel (2013), "Bargaining and Welfare : A Dynamic Structural Analysis of the Autorickshaw Market," Working Paper

Larsen, Bradley (2013), "The Efficiency of Dynamic, Post-Auction Bargaining: Evidence from Wholesale Used-Auto Auctions," Working Paper

Limao, Nuno (2006), "Preferential Trade Agreements as Stumbling Blocks for Multilateral Trade Liberalization: Evidence for the U.S.," American Economic Review 96(3): 896-914

Limao, Nuno (2007), "Are Preferential Trade Agreements with Non-trade Objectives a Stumbling Block for Multilateral Liberalization?" Review of Economic Studies 74(3): 821-55

Ludema, Rodney D. and Anna Maria Mayda (2009), "Do Countries Free Ride on MFN?," Journal of International Economics 77(2): 137-50

Ludema, Rodney and Anna Maria Mayda (2013), "Do Terms-of-Trade Effects Matter for Trade Agreements? Theory and Evidence from WTO countries," Quarterly Journal of Economics $128(4)$ 
Mayer Wolfgang (1981), "Theoretical Considerations on Negotiated Tariff Adjustments," Oxford Economic Papers 33(1): 135-53

Ossa, Ralph (2014), "Trade Wars and Trade Talks with Data," American Economic Review 104(12): $4104-46$

Rauch, James E. (1999), "Networks Versus Markets in International Trade," Journal of International Economics 48(1) : 7-35

New York Times (1950a), "Tariff Parley Off To A Good Start: 20 or 30 Negotiations to Open at Torquay This Week-U.S. in a Position to Bargain," Special to The New York Times by Michael L. Hoffman, dateline October 1; published October 2

New York Times (1950b), "French Now Seek New Tariff Duties: Torquay Trade Body Amazed as Paris Negates Efforts to Relax Import Curbs," Special to The New York Times by Michael L. Hoffman, dateline November 8; published November 10

New York Times (1951a), "U.S.-British Trade Talks Fail: Imperial Preference Blamed," Special Press Report to The New York Times by Michael L. Hoffman, dateline March 30; published March 31

New York Times (1951b), "Big Tariff Parley Nearing Its Close: 1,000 Experts at Torquay See New Convention Ready for Signatures by April 20," Special to The New York Times by Michael L. Hoffman, dateline March 11; published March 12

Nicita, Alessandro, Olarreaga, Marcelo and Peri Silva (2014), "Cooperation in WTO's Tariff Waters," mimeo, May.

Staiger, Robert W. (1995), "A Theory of Gradual Trade Liberalization," in Deardorff, A., Levinsohn, J., and Stern, R. (eds.) New Directions in Trade Theory, Univ of Mich Press

United Nations (1952), Treaties and International Agreements Registered or Filed and Recorded with the Secretariat of the United Nations, Vol 144 No 814 (VIII)

United States Council of the International Chamber of Commerce (1955), G.A.T.T.: An analysis and appraisal of the General Agreement on Tariffs and Trade. Prepared by the William L. Clayton Center for International Economic Affairs of the Fletcher School of Law and Diplomacy, February. 
United States Department of State (1950), Secret Memorandum: Memorandum by the Chairman of the Interdepartmental Committee on Trade Agreements (Corse) to the President. Foreign Relations of the United States, 1950 Volume 1, National Security Affairs; Foreign Economic Policy, Document 282, September 26, Washington DC.

United States Department of State (1951a), Secret Cable: Mr E.T. Casdagli of the United Kingdom Delegation to the Torquay Conference to Mr. James H. Lewis of the Untied States Delegation. Foreign Relations of the United States, 1951 Volume 1, National Security Affairs; Foreign Economic Policy, Document 470, March 14, Torquay England.

United States Department of State (1951b), Preliminary Analysis of Torquay Protocol of Accession, Schedules, and Related Documents: General Agreement on Tariffs and Trade. US Government Printing Office, Washington, DC.

WTO (2001), Guidelines and Procedures for the Negotiations on Trade in Services, March 28

WTO (2002), WTO Seminar on the GATS: Technical Aspects of Requests and Offers, February 20

WTO Appellate Body (2004), United States-Anti-Dumping Act of 1916-Recourse to arbitration by the United States under 22.6 of the DSU. WT/DS136/ARB, 24 February 


\section{Tables}

\begin{tabular}{rrrrr}
\hline \hline & Mean & SD & Min & Max \\
\hline Unconditional & & & & \\
N offers per good-country & 1.617 & 0.558 & 1 & 3 \\
N offers per country & 2.550 & 1.356 & 1 & 5 \\
N requests per good-country & 1.003 & 0.054 & 1 & 2 \\
N requests per country & 1.150 & 0.489 & 1 & 3 \\
\hline Conditional on final agreement & & & & \\
N offers per good-country & 1.965 & 0.379 & 1 & 3 \\
N offers per country & 3.067 & 1.163 & 2 & 5 \\
N requests per good-country & 1.009 & 0.094 & 1 & 2 \\
N requests per country & 1.214 & 0.579 & 1 & 3 \\
\hline \hline
\end{tabular}

Table 1: Sales by US: This table presents statistics on the amount of back and forth on goods and with negotiating partners over US concessions.

\begin{tabular}{rcccc}
\hline \hline & Mean & SD & Min & Max \\
\hline Unconditional & & & & \\
N offers per good-country & 1.433 & 0.538 & 1 & 5 \\
N offers per country & 2.100 & 1.071 & 1 & 6 \\
N requests per good-country & 1.005 & 0.074 & 1 & 2 \\
N requests per country & 1.545 & 0.596 & 1 & 3 \\
\hline Conditional on final agreement & & & & \\
N offers per good-country & 1.639 & 0.546 & 1 & 5 \\
N offers per country & 2.400 & 1.056 & 2 & 6 \\
N requests per good-country & 1.008 & 0.088 & 1 & 2 \\
N requests per country & 1.733 & 0.594 & 1 & 3 \\
\hline \hline
\end{tabular}

Table 2: Purchases by US: This table presents statistics on the amount of back and forth on goods and with negotiating partners over concessions from the negotiating partner. 


\begin{tabular}{|c|c|c|c|c|c|c|}
\hline & \multirow[b]{2}{*}{ Unique } & \multirow[b]{2}{*}{ Total } & \multicolumn{4}{|c|}{ By Negotiating Partner } \\
\hline & & & Mean & SD & Min & Max \\
\hline \multicolumn{7}{|l|}{ Sales } \\
\hline HS6 requests & 2586 & 4387 & 182.792 & 384.709 & 0 & 1692 \\
\hline HS6 request modifications & 65 & 65 & 2.708 & 11.323 & 0 & 55 \\
\hline HS6 offers & 1769 & 2635 & 109.792 & 195.404 & 0 & 783 \\
\hline HS6 offer modifications & 218 & 225 & 9.375 & 19.882 & 0 & 77 \\
\hline HS6 offers on requests & 1357 & 1107 & 46.125 & 87.097 & 0 & 349 \\
\hline Fraction HS6 offers on requests & 0.767 & & 0.315 & 0.282 & 0 & 1 \\
\hline HS6 offers without request & 412 & 1528 & 63.667 & 114.024 & 0 & 434 \\
\hline Fraction HS6 offers without request & 0.233 & & 0.518 & 0.339 & 0 & 1 \\
\hline HS6 final concessions & 1260 & 1589 & 66.208 & 126.891 & 0 & 475 \\
\hline HS6 final concessions with requests & 962 & 680 & 28.333 & 54.513 & 0 & 174 \\
\hline Fraction final concession with request & 0.763 & & 0.263 & 0.292 & 0 & 1 \\
\hline HS6 final concession without request & 298 & 909 & 37.875 & 79.459 & 0 & 308 \\
\hline Fraction final concessions without request & 0.237 & & 0.362 & 0.353 & 0 & 1 \\
\hline \multicolumn{7}{|l|}{ Purchases } \\
\hline HS6 requests & 2298 & 5104 & 212.667 & 188.645 & 0 & 667 \\
\hline HS6 request modifications & 436 & 496 & 20.667 & 55.038 & 0 & 267 \\
\hline HS6 offers & 1844 & 3665 & 152.708 & 168.606 & 0 & 574 \\
\hline HS6 offer modifications & 264 & 270 & 11.250 & 29.846 & 0 & 114 \\
\hline HS6 offers on requests & 1595 & 2793 & 116.375 & 130.484 & 0 & 555 \\
\hline Fraction HS6 offers on requests & 0.865 & & 0.634 & 0.402 & 0 & 1 \\
\hline HS6 offers without request & 249 & 872 & 36.333 & 80.429 & 0 & 379 \\
\hline Fraction HS6 offers without request & 0.135 & & 0.200 & 0.293 & 0 & 1 \\
\hline HS6 final concessions & 1505 & 2396 & 99.833 & 166.179 & 0 & 574 \\
\hline HS6 final concessions with requests & 1302 & 1682 & 70.083 & 124.558 & 0 & 555 \\
\hline Fraction final concession with request & 0.865 & & 0.486 & 0.420 & 0 & 1 \\
\hline HS6 final concession without request & 203 & 714 & 29.750 & 78.763 & 0 & 371 \\
\hline Fraction final concessions without request & 0.135 & & 0.139 & 0.200 & 0 & 1 \\
\hline
\end{tabular}

Table 3: Sales and Purchases by US. Sales concern US tariffs. Purchases concern non-US tariffs. Requests correspond to negotiating partners seeking a tariff reduction. Offers correspond to a country offering a tariff reduction. Unique refers to the number of unique HS6 codes. Total refers to the number of HS6 code-country pairs. 


\begin{tabular}{|c|c|c|c|c|}
\hline \multicolumn{3}{|c|}{ Sales by US } & \multicolumn{2}{|l|}{ Purchases by US } \\
\hline $\mathrm{N}$ countries & $\mathrm{N}$ products & Fraction products & $\mathrm{N}$ products & Fraction products \\
\hline & \multicolumn{2}{|c|}{ Any request } & \multicolumn{2}{|c|}{ Any request } \\
\hline 1 & 1484 & 0.574 & 1163 & 0.506 \\
\hline 2 & 629 & 0.243 & 497 & 0.216 \\
\hline 3 & 287 & 0.111 & 251 & 0.109 \\
\hline 4 & 152 & 0.059 & 143 & 0.062 \\
\hline 5 & 29 & 0.011 & 97 & 0.042 \\
\hline 6 & 4 & 0.002 & 59 & 0.026 \\
\hline 7 & 1 & 0.000 & 25 & 0.011 \\
\hline 8 & & & 23 & 0.010 \\
\hline 9 & & & 10 & 0.004 \\
\hline 10 & & & 14 & 0.006 \\
\hline 11 & & & 2 & 0.001 \\
\hline 12 & & & 10 & 0.004 \\
\hline 13 & & & 4 & 0.002 \\
\hline & \multicolumn{2}{|c|}{ Any offer } & \multicolumn{2}{|c|}{ Any offer } \\
\hline 1 & 1151 & 0.651 & 991 & 0.537 \\
\hline 2 & 445 & 0.252 & 370 & 0.201 \\
\hline 3 & 111 & 0.063 & 231 & 0.125 \\
\hline 4 & 52 & 0.029 & 112 & 0.061 \\
\hline 5 & 8 & 0.005 & 73 & 0.040 \\
\hline 6 & 1 & 0.001 & 44 & 0.024 \\
\hline 7 & 1 & 0.001 & 22 & 0.012 \\
\hline 10 & & & 1 & 0.001 \\
\hline & \multicolumn{2}{|c|}{ Final Concession } & \multicolumn{2}{|c|}{ Final Concession } \\
\hline 1 & 987 & 0.783 & 961 & 0.639 \\
\hline 2 & 224 & 0.178 & 312 & 0.207 \\
\hline 3 & 42 & 0.033 & 150 & 0.100 \\
\hline 4 & 7 & 0.006 & 57 & 0.038 \\
\hline 5 & & & 17 & 0.011 \\
\hline 6 & & & 8 & 0.005 \\
\hline
\end{tabular}

Table 4: This table presents the number of negotiating partners associated with a product conditional on the product having any request, any offer, or a final concession. Sales concern US tariffs. Purchases concern non-US tariffs. 


\begin{tabular}{|c|c|c|c|c|c|c|c|}
\hline & \multicolumn{3}{|l|}{ Sales } & \multicolumn{3}{|l|}{ Purchases } \\
\hline & & Ad Val & Specific & All & Ad Val & Specific & All \\
\hline Initial Request & $\overline{\mathrm{N}}$ & 1402 & 7716 & 2118 & 2788 & 2117 & 4905 \\
\hline over & Mean & 0.615 & 0.648 & 0.626 & 0.645 & 0.820 & 0.721 \\
\hline \multirow[t]{3}{*}{ Existing Tariff } & $\mathrm{SD}$ & 0.167 & 0.199 & 0.179 & 0.202 & 0.244 & 0.238 \\
\hline & Min & 0.000 & 0.000 & 0.000 & 0.000 & 0.000 & 0.000 \\
\hline & Max & 1.000 & 1.000 & 1.000 & 1.000 & 1.000 & 1.000 \\
\hline \multirow{2}{*}{$\begin{array}{r}\text { Initial Offer } \\
\text { over }\end{array}$} & $\mathrm{N}$ & 423 & 197 & 620 & 691 & 953 & 1644 \\
\hline & Mean & 1.192 & 1.155 & 1.181 & 1.472 & 1.193 & 1.310 \\
\hline \multirow[t]{3}{*}{ Initial Request } & $\mathrm{SD}$ & 0.505 & 0.825 & 0.624 & 0.683 & 0.500 & 0.600 \\
\hline & Min & 0.033 & 0.000 & 0.000 & 0.000 & 0.000 & 0.000 \\
\hline & Max & 5.000 & 10.000 & 10.000 & 5.000 & 6.667 & 6.667 \\
\hline Finalized Concession & $\mathrm{N}$ & 399 & 167 & 566 & 543 & 924 & 1467 \\
\hline over & Mean & 1.195 & 1.083 & 1.162 & 1.291 & 1.190 & 1.227 \\
\hline \multirow[t]{3}{*}{ Initial Request } & SD & 0.541 & 0.560 & 0.549 & 0.444 & 0.531 & 0.503 \\
\hline & Min & 0.033 & 0.000 & 0.000 & 0.000 & 0.000 & 0.000 \\
\hline & Max & 5.000 & 4.571 & 5.000 & 3.571 & 8.000 & 8.000 \\
\hline \multirow{5}{*}{$\begin{array}{r}\text { Finalized Concession } \\
\text { over } \\
\text { Initial Offer }\end{array}$} & $\mathrm{N}$ & 1267 & 610 & 1877 & 1222 & 1122 & 2344 \\
\hline & Mean & 1.000 & 1.025 & 1.008 & 1.006 & 0.992 & 0.999 \\
\hline & $\mathrm{SD}$ & 0.066 & 0.437 & 0.255 & 0.192 & 0.269 & 0.232 \\
\hline & Min & 0.020 & 0.000 & 0.000 & 0.000 & 0.000 & 0.000 \\
\hline & Max & 1.714 & 10.000 & 10.000 & 2.933 & 5.500 & 5.500 \\
\hline \multirow{5}{*}{$\begin{array}{r}\text { Finalized Concession } \\
\text { over } \\
\text { Existing Tariff }\end{array}$} & $\mathrm{N}$ & 1273 & 608 & 1881 & 1240 & 1170 & 2410 \\
\hline & Mean & 0.673 & 0.678 & 0.675 & 0.878 & 0.897 & 0.887 \\
\hline & SD & 0.184 & 0.196 & 0.188 & 0.192 & 0.206 & 0.199 \\
\hline & Min & 0.008 & 0.333 & 0.008 & 0.000 & 0.000 & 0.000 \\
\hline & Max & 1 & 1 & 1 & 1 & 1 & 1 \\
\hline
\end{tabular}

Table 5: This table conveys requests, offers, concessions and existing tariffs in proportion to each other. Some goods appear in both the ad valorem and specific columns. Sales concern US tariffs. Purchases concern non-US tariffs. 


\begin{tabular}{rrrrrr}
\hline & N & Mean & SD & Min & Max \\
\hline \hline Sales by US: Earliest Request over Final Request (AdVal.) & 774 & 1.042 & 0.389 & 0.315 & 10.000 \\
Sales by US: Earliest Request over Final Request (Sp.) & 409 & 1.020 & 0.494 & 0.000 & 9.167 \\
Sales by US: Earliest Request over Final Request (All) & 1183 & 1.035 & 0.428 & 0.000 & 10.000 \\
Sales by US: Earliest Offer over Final Offer (AdVal.) & 1107 & 1.006 & 0.307 & 0.146 & 9.333 \\
Sales by US: Earliest Offer over Final Offer (Sp.) & 497 & 0.988 & 0.236 & 0 & 2.743 \\
Sales by US: Earliest Offer over Final Offer (All) & 1604 & 1.001 & 0.287 & 0 & 9.333 \\
Purchases by US: Earliest Request over Final Request (AdVal.) & 502 & 1.124 & 0.701 & 0 & 7.000 \\
Purchases by US: Earliest Request over Final Request (Sp.) & 244 & 1.160 & 1.204 & 0 & 8.567 \\
Purchases by US: Earliest Request over Final Request (All) & 746 & 1.136 & 0.897 & 0 & 8.567 \\
Purchases by US: Earliest Offer over Final Offer (AdVal.) & 369 & 1.262 & 0.817 & 0 & 6 \\
Purchases by US: Earliest Offer over Final Offer (Sp.) & 527 & 1.068 & 0.572 & 0 & 9.066 \\
Purchases by US: Earliest Offer over Final Offer (All) & 896 & 1.148 & 0.690 & 0 & 9.066 \\
\hline \hline
\end{tabular}

Table 6: Ratio of final requests and offers to earliest requests and offers. "AdVal." denotes Ad Valorem. "Sp." denotes Specific. Sales concern US tariffs. Purchases concern non-US tariffs.

\begin{tabular}{rr}
\hline \hline HS6 received request and made request & 1293 \\
HS6 made offer and made request & 829 \\
HS6 received offer and received request & 972 \\
HS6 received request or made offer and made request or received offer (same country) & 444 \\
HS6 made and received a final concession (same country) & 78 \\
Fraction for which US made and received a final concession (same country) & 0.176 \\
\hline \hline
\end{tabular}

Table 7: Sales and Purchases by US. This table represents goods for which the US was both offering tariff reductions, and seeking tariff reductions, sometimes with the same negotiating partner. 


\begin{tabular}{lccccc}
\hline \hline \multicolumn{1}{c}{ Variable } & Obs & Mean & Std. Dev. & Min & Max \\
\hline By HS6 product & & & & & \\
N Suppliers to US & 3064 & 10.539 & 11.321 & 1 & 118 \\
N Suppliers to US at Torquay & 3064 & 6.507 & 5.536 & 0 & 36 \\
Torquay Volume Share & 3064 & 0.772 & 0.31 & 0 & 1 \\
HHI of Suppliers (HHI) & 3064 & 0.652 & 0.271 & 0 & 1 \\
Supply Absent from Torquay (ABSENT) & 3064 & 0.228 & 0.31 & 0 & 1 \\
Undifferentiated (UNDIFF) & 3064 & 0.322 & 0.467 & 0 & 1 \\
log( $\omega$ ) & 2694 & .385 & 2.165 & -5.63 & 7.134 \\
UK Preferences (PTA) & 3064 & 0.531 & 0.499 & 0 & 1 \\
Requested Product (REQ) & 3064 & 0.677 & 0.468 & 0 & 1 \\
Annecy Binding (PRVBND) & 3064 & 0.125 & 0.331 & 0 & 1 \\
By Country & & & & & 1 \\
Total Volume & 134 & 52415364 & $1.53 \mathrm{E}+08$ & 15 & $1.55 \mathrm{E}+09$ \\
Total Volume at Torquay & 36 & $1.3 \mathrm{E}+08$ & $2.68 \mathrm{E}+08$ & 1561595 & $1.55 \mathrm{E}+09$ \\
By HS6 product that US made an offer on or received a request for at Torquay & \\
Torquay Volume Share & 2423 & 0.78 & 0.292 & 0 & 1 \\
HHI of Suppliers (HHI) & 2423 & 0.625 & 0.262 & 0 & 1 \\
Supply Absent from Torquay (ABSENT) & 2423 & 0.22 & 0.292 & 0 & 1 \\
Undifferentiated (UNDIFF) & 2423 & 0.291 & 0.454 & 0 & 1 \\
log( $\omega$ ) & 2177 & 0.425 & 2.217 & -5.63 & 7.134 \\
WANT (Offer Stage) & 1636 & 2.757 & 7.594 & 0.713 & 185 \\
WANT (Failure Stage) & 2423 & 1.722 & 4.908 & 0.000 & 61.667 \\
UK Preferences (PTA) & 2423 & 0.529 & 0.499 & 0 & 1 \\
Requested Product (REQ) & 2423 & 0.856 & 0.351 & 0 & 1 \\
Annecy Binding (PRVBND) & 2423 & 0.131 & 0.338 & 0 & 1 \\
\hline
\end{tabular}

Table 8: Trade Data Summary Statistics. $\log (\omega)$ is the $\log$ inverse foreign export supply elasticity as estimated by Broda, Limao, and Weinstein (2008) for the US at the HS4 level. 


\begin{tabular}{rrrrr}
\hline \hline & \multicolumn{2}{c}{ US Offers } & \multicolumn{2}{c}{ US Requests } \\
\hline Torquay Rank & N HS6 & Fraction & N HS6 & Fraction \\
1 & 709 & 0.4334 & 1102 & 0.5311 \\
2 & 344 & 0.2103 & 721 & 0.3475 \\
3 & 179 & 0.1094 & 485 & 0.2337 \\
4 & 98 & 0.0599 & 298 & 0.1436 \\
5 & 57 & 0.0348 & 208 & 0.1002 \\
6 & 33 & 0.0202 & 140 & 0.0675 \\
7 & 26 & 0.0159 & 81 & 0.0390 \\
8 & 22 & 0.0134 & 54 & 0.0260 \\
$>8$ & 38 & 0.0232 & 78 & 0.0376 \\
\hline \multicolumn{4}{c}{ US Offers } & US Requests \\
Overall Rank & N HS6 & Fraction & N HS6 & Fraction \\
1 & 828 & 0.5061 & 1348 & 0.6496 \\
2 & 518 & 0.3166 & 876 & 0.4222 \\
3 & 300 & 0.1834 & 649 & 0.3128 \\
4 & 196 & 0.1198 & 482 & 0.2323 \\
5 & 139 & 0.0850 & 358 & 0.1725 \\
6 & 103 & 0.0630 & 276 & 0.1330 \\
7 & 62 & 0.0379 & 202 & 0.0973 \\
8 & 42 & 0.0257 & 152 & 0.0733 \\
$>8$ & 205 & 0.1253 & 588 & 0.2834 \\
\hline
\end{tabular}

Table 9: Number and fraction of offers and requests not going to a supplier by supplier rank in US imports for HS6 code. The top panel uses the rank amongst Torquay participants. The bottom panel uses the rank amongst all suppliers. 


\begin{tabular}{|c|c|c|c|c|}
\hline & \multicolumn{2}{|c|}{ US Offers } & \multicolumn{2}{|c|}{ US Requests } \\
\hline Torquay Rank & N HS6 & Fraction & N HS6 & Fraction \\
\hline 1 & 927 & 0.3745 & 976 & 0.2670 \\
\hline 2 & 561 & 0.2267 & 604 & 0.1653 \\
\hline 3 & 343 & 0.1386 & 473 & 0.1294 \\
\hline 4 & 238 & 0.0962 & 444 & 0.1215 \\
\hline 5 & 127 & 0.0513 & 308 & 0.0843 \\
\hline 6 & 93 & 0.0376 & 261 & 0.0714 \\
\hline 7 & 48 & 0.0194 & 201 & 0.0550 \\
\hline 8 & 36 & 0.0145 & 134 & 0.0367 \\
\hline$>8$ & 102 & 0.0412 & 254 & 0.0695 \\
\hline & \multicolumn{2}{|c|}{ US Offers } & \multicolumn{2}{|c|}{ US Requests } \\
\hline Overall Rank & N HS6 & Fraction & N HS6 & Fraction \\
\hline 1 & 808 & 0.3265 & 727 & 0.1989 \\
\hline 2 & 461 & 0.1863 & 633 & 0.1732 \\
\hline 3 & 338 & 0.1366 & 386 & 0.1056 \\
\hline 4 & 231 & 0.0933 & 350 & 0.0958 \\
\hline 5 & 170 & 0.0687 & 311 & 0.0851 \\
\hline 6 & 97 & 0.0392 & 247 & 0.0676 \\
\hline 7 & 93 & 0.0376 & 185 & 0.0506 \\
\hline 8 & 58 & 0.0234 & 164 & 0.0449 \\
\hline$>8$ & 219 & 0.0885 & 652 & 0.1784 \\
\hline
\end{tabular}

Table 10: Number and fraction of offers and requests by supplier rank in US imports for HS6 code. The top panel uses the rank amongst Torquay participants. The bottom panel uses the rank amongst all suppliers. 


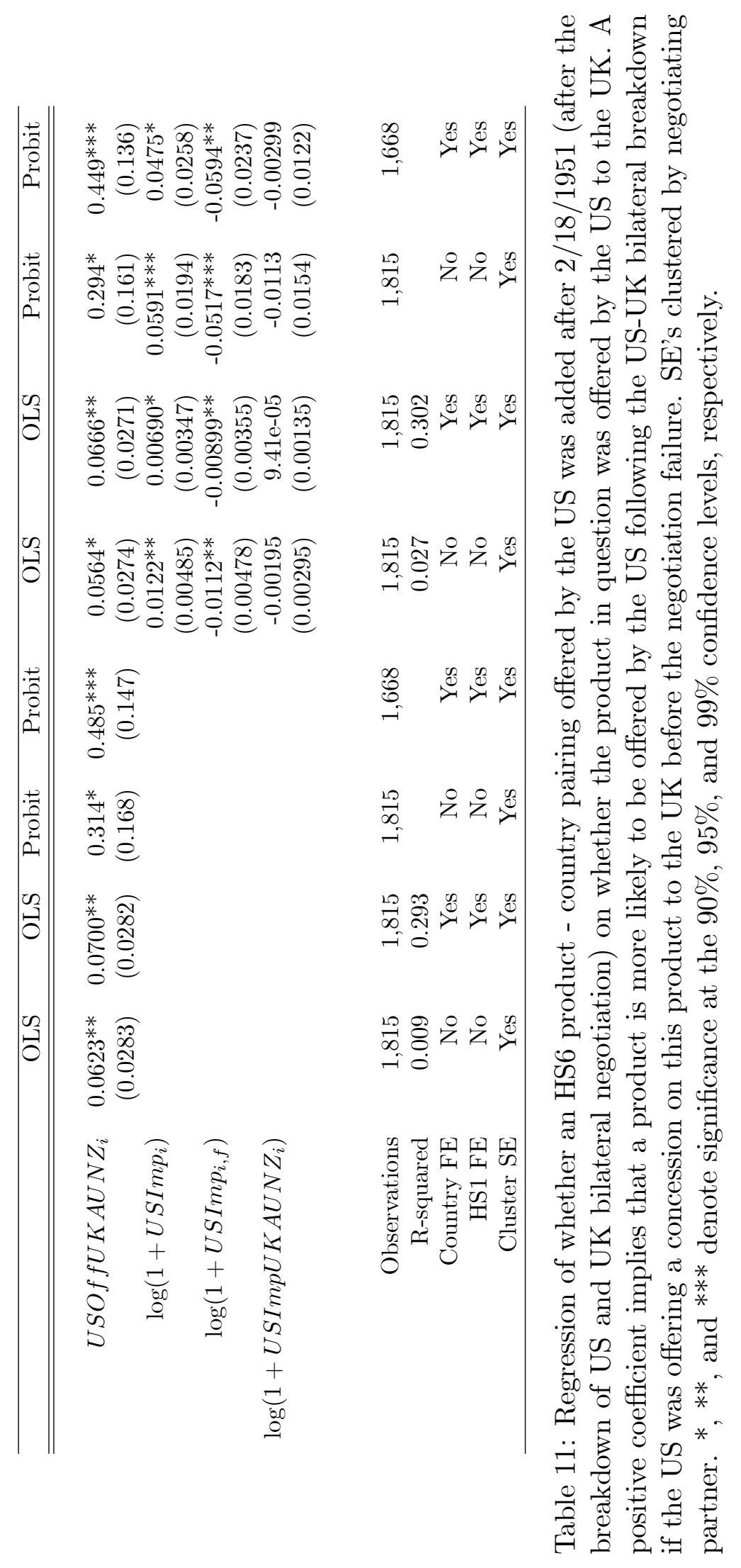




\begin{tabular}{|c|c|c|c|c|c|c|c|c|}
\hline & $\begin{array}{r}\text { Offer } \\
\text { Probit }\end{array}$ & $\begin{array}{r}\text { Failure } \\
\text { OLS }\end{array}$ & $\begin{array}{r}\text { Failure } \\
\text { OLS }\end{array}$ & $\begin{array}{r}\text { Failure } \\
\text { OLS }\end{array}$ & $\begin{array}{r}\text { Offer } \\
\text { Probit }\end{array}$ & $\begin{array}{r}\text { Failure } \\
\text { OLS }\end{array}$ & $\begin{array}{r}\text { Failure } \\
\text { OLS }\end{array}$ & $\begin{array}{r}\text { Failure } \\
\text { OLS }\end{array}$ \\
\hline HHI & $\begin{array}{r}0.774 \\
(0.474)\end{array}$ & $\begin{array}{r}0.990 * * * \\
(0.250)\end{array}$ & $\begin{array}{r}1.019 * * * \\
(0.272)\end{array}$ & $\begin{array}{r}0.842^{* * *} \\
(0.257)\end{array}$ & $\begin{array}{r}0.830 \\
(0.515)\end{array}$ & $\begin{array}{r}0.831^{* * *} \\
(0.267)\end{array}$ & $\begin{array}{r}0.891^{* * *} \\
(0.286)\end{array}$ & $\begin{array}{r}0.636^{* *} \\
(0.278)\end{array}$ \\
\hline$H H I^{2}$ & $\begin{array}{r}-0.976^{* *} \\
(0.372)\end{array}$ & $\begin{array}{r}-0.616^{* * *} \\
(0.196)\end{array}$ & $\begin{array}{r}-0.651^{* * *} \\
(0.234)\end{array}$ & $\begin{array}{r}-0.531^{* * *} \\
(0.204)\end{array}$ & $\begin{array}{r}-1.045^{* *} \\
(0.401)\end{array}$ & $\begin{array}{r}-0.467^{* *} \\
(0.209)\end{array}$ & $\begin{array}{r}-0.543^{* *} \\
(0.242)\end{array}$ & $\begin{array}{r}-0.337 \\
(0.219)\end{array}$ \\
\hline WANT & $\begin{array}{r}0.0245^{* * *} \\
(0.00753)\end{array}$ & $\begin{array}{c}-0.00257^{*} \\
(0.000978)\end{array}$ & $\begin{array}{r}-0.00232 \\
(0.00126)\end{array}$ & $\begin{array}{r}-0.00164 \\
(0.001000)\end{array}$ & $\begin{array}{r}0.0277^{* * *} \\
(0.00864)\end{array}$ & $\begin{array}{r}-0.00248 \\
(0.000949)\end{array}$ & $\begin{array}{r}-0.00193 \\
(0.00123)\end{array}$ & $\begin{array}{r}-0.00197 \\
(0.00110)\end{array}$ \\
\hline ABSENT & $\begin{array}{c}-0.192^{* *} \\
(0.0963)\end{array}$ & $\begin{array}{r}0.0922^{* *} \\
(0.0485)\end{array}$ & $\begin{array}{c}0.0852^{*} \\
(0.0546)\end{array}$ & $\begin{array}{c}0.0834^{*} \\
(0.0471)\end{array}$ & $\begin{array}{r}-0.167 \\
(0.103)\end{array}$ & $\begin{array}{r}0.0990^{* *} \\
(0.0511)\end{array}$ & $\begin{array}{r}0.0863^{*} \\
(0.0553)\end{array}$ & $\begin{array}{c}0.0852^{*} \\
(0.0495)\end{array}$ \\
\hline PTA & $\begin{array}{r}0.318^{* * *} \\
(0.0602) \\
0.552^{* * *} \\
(0.0554)\end{array}$ & $\begin{array}{r}0.0826^{* * *} \\
(0.0261) \\
0.0128 \\
(0.0274)\end{array}$ & $\begin{array}{r}0.0935^{* *} \\
(0.0442) \\
0.0363 \\
(0.0819)\end{array}$ & $\begin{array}{r}0.0609^{* *} \\
(0.0273)\end{array}$ & $\begin{array}{r}0.363^{* * *} \\
(0.0646) \\
0.504^{* * *} \\
(0.0605)\end{array}$ & $\begin{array}{r}0.0718^{* * *} \\
(0.0277) \\
0.0368 \\
(0.0292)\end{array}$ & $\begin{array}{r}0.0968^{* *} \\
(0.0463) \\
0.0803 \\
(0.0715)\end{array}$ & $\begin{array}{r}0.0371 \\
(0.0301)\end{array}$ \\
\hline PrevBound & $\begin{array}{r}0.215^{* * *} \\
(0.0739)\end{array}$ & $\begin{array}{r}-0.0719^{* *} \\
(0.0297)\end{array}$ & $\begin{array}{c}-0.0647^{*} \\
(0.0383)\end{array}$ & $\begin{array}{r}-0.0845^{* * *} \\
(0.0291)\end{array}$ & $\begin{array}{c}0.207^{* *} \\
(0.0799)\end{array}$ & $\begin{array}{c}-0.0571^{*} \\
(0.0316)\end{array}$ & $\begin{array}{c}-0.0433 \\
(0.0375)\end{array}$ & $\begin{array}{r}-0.0844^{* *} \\
(0.0316)\end{array}$ \\
\hline $\begin{array}{l}\text { UNDIFF } \\
\qquad \log (\omega)\end{array}$ & $\begin{array}{r}0.0457 \\
(0.0608)\end{array}$ & $\begin{array}{r}-0.105^{* * *} \\
(0.0270)\end{array}$ & $\begin{array}{r}-0.103^{* * *} \\
(0.0276)\end{array}$ & $\begin{array}{r}-0.118^{* * *} \\
(0.0231)\end{array}$ & $\begin{array}{r}0.0560 \\
(0.0666) \\
0.0539^{* * *} \\
(0.0131)\end{array}$ & $\begin{array}{r}-0.124^{* * *} \\
(0.0306) \\
-0.0122^{* *} \\
(0.00569)\end{array}$ & $\begin{array}{r}-0.120 * * * \\
(0.0315) \\
-0.00853 \\
(0.00787)\end{array}$ & $\begin{array}{r}-0.152^{* * *} \\
(0.0266) \\
-0.0271^{* * *} \\
(0.00563)\end{array}$ \\
\hline$\hat{\lambda}$ & & & 0.0626 & $\begin{array}{r}-0.0171 \\
(0.209)\end{array}$ & $(0.0586)$ & & 0.127 & $\begin{array}{r}-0.0847 \\
(0.193)\end{array}$ \\
\hline Observations & 3,064 & 1,636 & 1,636 & 1,636 & 2,694 & 1,456 & 1,456 & 1,456 \\
\hline $\begin{array}{r}\text { R-squared } \\
\text { HS1 FE }\end{array}$ & Y & $\begin{array}{r}0.109 \\
Y\end{array}$ & $\begin{array}{r}0.109 \\
\mathrm{Y}\end{array}$ & $\begin{array}{r}0.040 \\
\mathrm{~N}\end{array}$ & Y & $\begin{array}{r}0.127 \\
\mathrm{Y}\end{array}$ & $\begin{array}{r}0.127 \\
\mathrm{Y}\end{array}$ & $\begin{array}{r}0.053 \\
\mathrm{~N}\end{array}$ \\
\hline
\end{tabular}

Table 12: Offer and failure equations conditional on theoretical predictors. Columns 1 and 5 correspond to the offer equation, estimated as a Probit. Columns 2-4 and 6-8 correspond to failure equations. Columns 2 and 6 do not make any selection correction. Columns 3 and 7 use the inverse Mills ratio from the offer equation, but no excluded variables. Columns 4 and 8 exclude REQ and HS1 fixed effects from the failure equation. Columns 1-4 omit $\omega$, the market power measure as it is not available for all products. WANT is defined with respect to the principal supplier in the offer regression, whereas it is defined with respect to the highest US import volume (for the good in question) country who received the offer in the failure regression. Robust standard errors in parentheses. *, **, and *** denote significance at the $90 \%, 95 \%$, and 99\% confidence levels, respectively. 